\title{
Explaining variance in black carbon's aging timescale
}

\author{
L. Fierce ${ }^{1}$, N. Riemer ${ }^{2}$, and T. C. Bond ${ }^{1}$ \\ ${ }^{1}$ Department of Civil and Environmental Engineering, University of Illinois at Urbana-Champaign, Urbana, Illinois, USA \\ ${ }^{2}$ Department of Atmospheric Sciences, University of Illinois at Urbana-Champaign, Urbana, Illinois, USA
}

Correspondence to: N. Riemer (nriemer@illinois.edu)

Received: 13 June 2014 - Published in Atmos. Chem. Phys. Discuss.: 16 July 2014

Revised: 15 November 2014 - Accepted: 16 January 2015 - Published: 20 March 2015

\begin{abstract}
The size and composition of particles containing black carbon (BC) are modified soon after emission by condensation of semivolatile substances and coagulation with other particles, known collectively as "aging" processes. Although this change in particle properties is widely recognized, the timescale for transformation is not well constrained. In this work, we simulated aerosol aging with the particle-resolved model PartMC-MOSAIC (Particle Monte Carlo - Model for Simulating Aerosol Interactions and Chemistry) and extracted aging timescales based on changes in particle cloud condensation nuclei (CCN). We simulated nearly 300 scenarios and, through a regression analysis, identified the key parameters driving the value of the aging timescale. We show that BC's aging timescale spans from hours to weeks, depending on the local environmental conditions and the characteristics of the fresh $\mathrm{BC}$ containing particles. Although the simulations presented in this study included many processes and particle interactions, we show that $80 \%$ of the variance in the aging timescale is explained by only a few key parameters. The condensation aging timescale decreased with the flux of condensing aerosol and was shortest for the largest fresh particles, while the coagulation aging timescale decreased with the total number concentration of large $(D>100 \mathrm{~nm}), \mathrm{CCN}$-active particles and was shortest for the smallest fresh particles. Therefore, both condensation and coagulation play important roles in aging, and their relative impact depends on the particle size range.
\end{abstract}

\section{Introduction}

Particles containing black carbon (BC) alter Earth's energy balance by scattering and absorbing solar radiation (McCormick and Ludwig, 1967; Rosen et al., 1978; Schulz et al., 2006), by interacting with clouds (Twomey, 1977; Twomey et al., 1984; Lohmann et al., 2005; Albrecht, 1989; Ackerman et al., 2000), and by decreasing the albedo of ice and snow (Hansen and Nazarenko, 2004; Jacobson, 2004). Each of these climate effects depends on the properties of individual BC-containing particles and their atmospheric residence time. The dominant removal mechanism of $\mathrm{BC}$ mass from the atmosphere is wet deposition (Cozic et al., 2007), with one important pathway being the activation of $\mathrm{BC}$-containing particles into cloud condensation nuclei $(\mathrm{CCN})$ and their subsequent removal if the cloud precipitates. Although freshly emitted BC-containing particles are too small and hydrophobic to activate (Maricq, 2007; Weingartner et al., 1997), their morphology and chemical composition are altered soon after emission by condensation of semivolatile gases and coagulation with preexisting particles (Johnson et al., 2005; Oshima et al., 2009; Zaveri et al., 2010).

These changes in particle characteristics, termed "aging", often increase the particles' susceptibility to cloud droplet nucleation and wet removal (Furutani et al., 2008; Cantrell et al., 2001; Zuberi et al., 2005), so these processes must be included in global models. However, a complex aerosol population that evolves with time is not easily simulated in climate models; so, even sophisticated aerosol schemes do not fully resolve aerosol properties on a per-particle level (Jacobson, 1997; Wexler et al., 1994; Bauer et al., 2008; Binkowski and Roselle, 2003; McGraw, 1997; Jacobson, 2002; Aquila et al., 2011; Matsui et al., 2013). The simplest representation of aging classifies BC mass as either hydrophobic or 
hydrophilic, such that hydrophilic BC is susceptible to removal by wet deposition and hydrophobic $\mathrm{BC}$ is not. In this framework, BC is transferred from the hydrophobic (fresh) category to the hydrophilic (aged) category according to a first-order aging timescale (Cooke and Wilson, 1996; Croft et al., 2005; Koch, 2001). Global models apply a fixed aging timescale of 1-3 days. Global modeling studies have shown that estimates of BC's climate forcing are sensitive to the assumed aging timescale (Koch et al., 2009), but its value is not well constrained. While some climate models have been moving toward aerosol modules that represent aerosol aging using several interacting modes (Aquila et al., 2011; Bauer et al., 2008; Wilson et al., 2001; Matsui et al., 2013), the practice of using a fixed aging timescale is still widespread (Jo et al., 2013; Chin et al., 2014; Schmidt et al., 2014).

To improve upon using one constant value for the aging timescale, several studies have developed parameterizations of BC's aging timescale that vary with environmental conditions. Liu et al. (2011) developed a parameterization of black carbon aging by condensation that depended on the condensation rate of sulfuric acid and overall BC surface area. They showed that, by allowing for slower aging in the winter, their parameterization was better able to represent seasonal variability in black carbon transport to the Arctic. Oshima and Koike (2013) extended this approach and developed a parameterization of aging timescales based on simulations with a box model. Their parameterization predicted the rate for $\mathrm{BC}$ to transition from a hydrophobic class to a hydrophilic class, expressed as a function of the mass-normalized coating rate and the parameters of the fresh $\mathrm{BC}$ size distribution. Riemer et al. (2004) showed that timescales for aging by coagulation decrease with the overall aerosol number concentration, which they parameterized using a simple power law, and this parameterization was applied by Croft et al. (2005). Pierce et al. (2009) parameterized size-resolved coagulation rates as a first-order loss process that depends on the overall size distribution. In an analysis of aging timescales in a specific urban environment using a particle-resolved model, Riemer et al. (2010) showed that timescales for particles to transition from $\mathrm{CCN}$-inactive to $\mathrm{CCN}$-active varied diurnally due to variations in condensation aging rates. Because the timescale from Riemer et al. (2010) is based on changes in particle $\mathrm{CCN}$ activity, it quantifies changes in particle characteristics that these first-order aging models are meant to represent.

This study builds on the work of Riemer et al. (2010) to generalize how the CCN-based aging timescale varies with scenario-specific properties. Unlike other aerosol schemes, which simplify the representation of particle composition, the particle-resolved model tracks the composition of each simulated particle and is, therefore, uniquely suited to study the impact of aging on per-particle CCN activity. The focus of this paper is to identify the set of independent variables that best explain variance in BC's aging timescale for a large collection of simulations. Using the independent variables identified in this study, we will later introduce a simple aging parameterization for use in global models.

\section{Extracting aging timescales from particle-resolved model output}

In a first-order model of aging, particles transition from fresh to aged according to an aging timescale, $\tau_{\text {aging. In this frame- }}$ work, a criterion must be applied to distinguish fresh and aged particles. Particle CCN activity at a specified environmental supersaturation is the aging criterion applied in this work, so the aging timescale indicates changes in particles' susceptibility to removal by wet deposition. We define aged particles as those that are activated at a specified environmental supersaturation, and fresh particles are $\mathrm{CCN}$-inactive at that supersaturation threshold. The first-order aging model is given by

$\left[\frac{\mathrm{d} N_{\text {fresh }}}{\mathrm{d} t}\right]_{\text {aging }}=-\frac{1}{\tau_{\text {aging }}} N_{\text {fresh }}$,

where $N_{\text {fresh }}$ is the number concentration of fresh particles.

Before discussing the full set of sensitivity simulations in Sect. 3, we describe the particle-resolved simulation of aerosol dynamics in a baseline scenario and show how the aging timescale is used to quantify changes in per-particle $\mathrm{CCN}$ activity. The particle-resolved model is described in Sect. 2.1, and the $\kappa$-Köhler model (Petters and Kreidenweis, 2007) for computing CCN activity from the PartMCMOSAIC data is discussed in Sect. 2.2. We discuss methods for computing aging timescales from the particle-resolved model output in Sect. 2.3.

\subsection{Particle-resolved simulation of aerosol aging}

The Particle Monte Carlo model (Riemer et al., 2009) coupled to the Model for Simulating Aerosol Interactions and Chemistry (Zaveri et al., 2008), PartMC-MOSAIC, is a Lagrangian box model that simulates gas and aerosol chemistry, gas-aerosol mass transfer, aerosol coagulation, gas and aerosol emissions, and dilution with background air. The boundary layer height varies temporally according to a prescribed profile. The treatment of dilution is the same as in Riemer et al. (2009); a constant dilution rate of $1.5 \times 10^{-5} \mathrm{~s}^{-1}$ is applied and additional dilution with background air occurs when the boundary layer height increases. Coagulation events, particle emissions, and dilution with background air are simulated stochastically by PartMC. Gas- and aerosolphase chemistry and gas-aerosol mass transfer are simulated deterministically by MOSAIC. MOSAIC includes modules for gas-phase photochemistry (Zaveri and Peters, 1999), particle-phase thermodynamics (Zaveri et al., 2005b, a), and gas-particle mass transfer (Zaveri et al., 2008). MOSAIC treats secondary organic aerosol formation based on the SORGAM scheme (Schell et al., 2001). The coupled model 
represents all atmospherically important aerosol species, including sulfate $\left(\mathrm{SO}_{4}\right)$, nitrate $\left(\mathrm{NO}_{3}\right)$, chloride $(\mathrm{Cl})$, carbonate $\left(\mathrm{CO}_{3}\right)$, ammonium $\left(\mathrm{NH}_{4}\right)$, sodium $(\mathrm{Na})$, calcium $(\mathrm{Ca})$, methanesulfonic acid (MSA), black carbon (BC), primary organic aerosol (POA), and eight secondary organic aerosol (SOA) species. A full description of the coupled model can be found in Riemer et al. (2009). PartMC-MOSAIC represents changes in particle composition by condensation and coagulation; we do not consider changes in particle shape or aging by photochemical oxidation. PartMC version 2.1.4 was used to generate the results in this paper. Simulations were performed at a time step of $60 \mathrm{~s}$, with approximately $10^{4}$ computational particles.

We simulated 288 plume scenarios, varying meteorological conditions, emissions of gases and particles, and the background number concentration, with further description given in Sect. 3. The atmospheric composition and environmental conditions differed between the scenarios, but the general structure of all simulations was the same. In each case, we simulated a well-mixed air parcel that is advected over and away from a large urban area. All scenarios started at 06:00 LST (local standard time), at which time the parcel contained only background gas and aerosol without any freshly emitted particles. During transport over the urban area, the parcel received gas and aerosol emissions from 06:00 LST until 18:00 LST, after which all emissions ceased. In these scenarios, we simulate a well-mixed boundary layer during the day, and the parcel is assumed to be in the residual layer at night. The temperature, mixing height, and relative humidity were held constant. Before discussing the full set of scenarios in Sect. 3, we show changes in CCN activity and the diurnal evolution of aging timescales in a baseline scenario. For this baseline scenario, Table 1 outlines background aerosol number concentration, aerosol emission intensity, and size distribution and composition information for both background and emitted aerosols. The background concentration and emission intensity of gas-phase species are provided in Table 2.

\section{$2.2 \kappa$-Köhler model for computing CCN activity}

We determined aging timescales from the particle-resolved results by tracking changes in CCN activity over two consecutive time steps. A particle's ability to activate cloud formation depends on its dry diameter $D_{\mathrm{dry}, i}$ and its hygroscopicity parameter $\kappa_{i}$. The equilibrium saturation ratio $\left(S_{i}\right)$ over an aqueous droplet is computed through the $\kappa$-Köhler model (Köhler, 1936; Petters and Kreidenweis, 2007) as

$S_{i}\left(D_{i}\right)=\frac{D_{i}^{3}-D_{\mathrm{dry}, i}^{3}}{D_{i}^{3}-D_{\mathrm{dry}, i}^{3}\left(1-\kappa_{i}\right)} \exp \left(\frac{4 \sigma_{\mathrm{w}} M_{\mathrm{w}}}{R T \rho_{\mathrm{w}} D_{i}}\right)$,

where $\sigma_{\mathrm{w}}$ is the surface tension of water, $M_{\mathrm{w}}$ is the molecular weight of water, $R$ is the universal gas constant, $T$ is the ambient temperature, $\rho_{\mathrm{w}}$ is the density of water, $D_{i}$ is the particle wet diameter, $D_{\mathrm{dry}, i}$ is the particle dry diameter, and $\kappa_{i}$ is the hygroscopicity parameter introduced by Petters and Kreidenweis (2007). All other factors being equal, particles with a greater $\kappa_{i}$ are more hygroscopic and more easily activated. The parameter $\kappa$ has been determined empirically for a number of aerosol species (Table 3), and the effective hygroscopicity parameter $\kappa_{i}$ for each particle is the volume-weighted average of $\kappa$ for its constituent aerosol species. If a particle grows to its critical wet diameter $\left(D_{\mathrm{c}, i}\right)$, it will continue to grow without bound at that supersaturation and is said to be "activated". We denote the critical saturation ratio at which a particle activates and forms a cloud droplet with $S_{\mathrm{c}, i}=S_{i}\left(D_{\mathrm{c}, i}\right)$ and the critical supersaturation as $s_{\mathrm{c}, i}=\left(S_{\mathrm{c}, i}-1\right) \times 100$.

Figure 1 shows the two-dimensional number density distribution as a function of the particle dry diameter $\left(D_{\mathrm{dry}, i}\right)$ and the particle hygroscopicity parameter $\left(\kappa_{i}\right)$. Only particles containing $\mathrm{BC}$ are shown in this figure. In the scenarios presented in this study, all $\mathrm{BC}$ originated from diesel or gasoline exhaust. Choosing a certain environmental supersaturation threshold allows us to classify the particles as fresh or aged. For example, all particles to the left of the line for $s_{\mathrm{c}, i}=1 \%$ are considered "fresh" for environmental supersaturations of $1 \%$ or lower, and all particles to the right of the line for $s_{\mathrm{c}, i}=1 \%$ are considered "aged" at supersaturations above $1 \%$.

The number distributions corresponding to fresh emissions, prior to any aging, are shown in Fig. 1a, and changes in the distribution during two time periods are shown in Fig. $1 \mathrm{~b}$ and c. Freshly emitted combustion particles are small and hydrophobic, with geometric mean diameter $D_{\text {dry,gm }}=$ $0.5 \mu \mathrm{m}$ and with a hygroscopicity parameter of $\kappa_{i}=3 \times 10^{-4}$ or $\kappa_{i}=8 \times 10^{-4}$ for particles from diesel or gasoline, respectively. Therefore, most BC-containing particles are initially unable to activate at any environmental supersaturation $s<1 \%$ (lines in Fig. 1a). As $D_{\mathrm{dry}, i}$ and $\kappa_{i}$ for individual particles increase by condensation and coagulation, their critical supersaturation $s_{\mathrm{c}, i}$ for $\mathrm{CCN}$-active decreases, shown by particles crossing the lines of constant critical supersaturation in Fig. 1. Secondary aerosol forms through photochemical reactions during the day, causing rapid changes in particles' size and hygroscopicity. At night, aging by condensation is slow, so coagulation is the dominant aging mechanism. This diurnal variation in aging rates is consistent with observations (Rose et al., 2011; Cheng et al., 2012). We define particles that "age" over a specific time period as those that transition from $\mathrm{CCN}$-inactive to $\mathrm{CCN}$-active, that is, the particles that move from below a supersaturation line ( $\mathrm{CCN}$-inactive) at time $t$ to above supersaturation line (CCN-active) at $t+\Delta t$.

\subsection{CCN-based aging timescale}

For the entire particle population, this change in the particle properties is quantified using the first-order aging timescale defined in Eq. (1). Because the time period $\Delta t$ is short rela- 
Table 1. Aerosol emissions and initial conditions for baseline simulation.

\begin{tabular}{lrrrr}
\hline Initial/background & $N\left(\mathrm{~m}^{-3}\right)$ & $D_{\mathrm{gm}}(\mu \mathrm{m})$ & $\sigma_{\mathrm{g}}$ & Composition by mass \\
\hline Aitken mode & $9 \times 10^{8}$ & 0.02 & 1.45 & $50 \%\left(\mathrm{NH}_{4}\right)_{2} \mathrm{SO}_{4}, 50 \% \mathrm{SOA}$ \\
Accumulation mode & $7.5 \times 10^{8}$ & 0.116 & 1.65 & $50 \%\left(\mathrm{NH}_{4}\right)_{2} \mathrm{SO}_{4}, 50 \% \mathrm{SOA}$ \\
\hline Emissions & $\dot{N}_{\mathrm{emit}}\left(\mathrm{m}^{-2} \mathrm{~s}^{-1}\right)$ & $D_{\mathrm{gm}, \mathrm{emit}}(\mu \mathrm{m})$ & $\sigma_{\mathrm{g}}$ & Composition by mass \\
\hline Meat cooking & $9 \times 10^{6}$ & 0.0865 & 1.9 & $100 \%$ POA \\
Diesel vehicles & $3.2 \times 10^{7}$ & 0.05 & 1.7 & $30 \%$ POA, 70\% BC \\
Gasoline vehicles & $1 \times 10^{7}$ & 0.05 & 1.7 & $80 \%$ POA, $20 \% \mathrm{BC}$ \\
\hline
\end{tabular}

Table 2. Gas-phase initial conditions and emissions for baseline simulation.

\begin{tabular}{|c|c|c|c|}
\hline MOSAIC species & Symbol & $\begin{array}{r}\text { Initial mole } \\
\text { fraction (ppb) }\end{array}$ & $\begin{array}{r}\text { Emissions } \\
\left(\mathrm{nmol} \mathrm{m}^{-2} \mathrm{~s}^{-1}\right)\end{array}$ \\
\hline Nitric oxide & NO & 0.1 & 15.9 \\
\hline Nitrogen dioxide & $\mathrm{NO}_{2}$ & 1 & 0.84 \\
\hline Nitric acid & $\mathrm{HNO}_{3}$ & 1.0 & \\
\hline Ozone & $\mathrm{O}_{3}$ & 50 & \\
\hline Hydrogen peroxide & $\mathrm{H}_{2} \mathrm{O}_{2}$ & 1.1 & \\
\hline Carbon monoxide & $\mathrm{CO}$ & 21 & 291.3 \\
\hline Sulfur dioxide & $\mathrm{SO}_{2}$ & 0.8 & 7.53 \\
\hline Ammonia & $\mathrm{NH}_{3}$ & 0.5 & 6.11 \\
\hline Hydrogen chloride & $\mathrm{HCl}$ & 0.7 & \\
\hline Methane & $\mathrm{CH}_{4}$ & 2200 & \\
\hline Ethane & $\mathrm{C}_{2} \mathrm{H}_{6}$ & 1.0 & \\
\hline Formaldehyde & $\mathrm{HCHO}$ & 1.2 & 1.68 \\
\hline Methanol & $\mathrm{CH}_{3} \mathrm{OH}$ & 0.12 & 0.28 \\
\hline Methyl hydrogen peroxide & $\mathrm{CH}_{3} \mathrm{OOH}$ & 0.5 & \\
\hline Acetaldehyde & ALD2 & 1.0 & 0.68 \\
\hline Paraffin carbon & PAR & 2.0 & 96 \\
\hline Acetone & AONE & 1.0 & 1.23 \\
\hline Ethene & ETH & 0.2 & 7.3 \\
\hline Terminal olefin carbons & OLET & $2.3 \times 10^{-2}$ & 2.42 \\
\hline Internal olefin carbons & OLEI & $3.1 \times 10^{-4}$ & 2.42 \\
\hline Toluene & TOL & & 4.04 \\
\hline Xylene & XYL & 0.1 & 2.41 \\
\hline Lumped organic nitrate & ONIT & 0.1 & \\
\hline Peroxyacetyl nitrate & PAN & 0.8 & \\
\hline Higher organic acid & $\mathrm{RCOOH}$ & 0.2 & \\
\hline Higher organic peroxide & $\mathrm{ROOH}$ & $2.5 \times 10^{-2}$ & \\
\hline Isoprene & ISOP & 0.5 & 0.23 \\
\hline Alcohols & ANOL & & 3.45 \\
\hline
\end{tabular}

tive to the timescale $\tau_{\text {aging, }}$ Eq. (1) can be approximated as

$\left[\frac{\mathrm{d} N_{\mathrm{fresh}}}{\mathrm{d} t}\right]_{\text {aging }} \approx-\frac{\Delta N_{\mathrm{f} \rightarrow \mathrm{a}}}{\Delta t}$,

where $\Delta N_{\mathrm{f} \rightarrow \mathrm{a}}$ is the number of discrete particles that transition from fresh at time $t$ to aged at time $t+\Delta t$, calculated from changes in the number of fresh particles. In this study, aging timescales are computed over a time step $\Delta t=10 \mathrm{~min}$.
Combining Eqs. 1 and 3, the aging timescale is computed as

$\tau_{\text {aging }}(t, s) \approx \Delta t \frac{N_{\text {fresh }}(t, s)}{\Delta N_{\mathrm{f} \rightarrow \mathrm{a}}(t, t+\Delta t, s)}$.

We refer to this aging timescale as the "bulk aging timescale" because it corresponds to the entire fresh particle population, and the term $\Delta N_{\mathrm{f} \rightarrow \mathrm{a}}$ includes all particles that transition from fresh to aged, regardless of their size. Later, we will introduce an analogous "size-resolved aging timescale". Further details on the derivation of the bulk aging timescale, including num- 


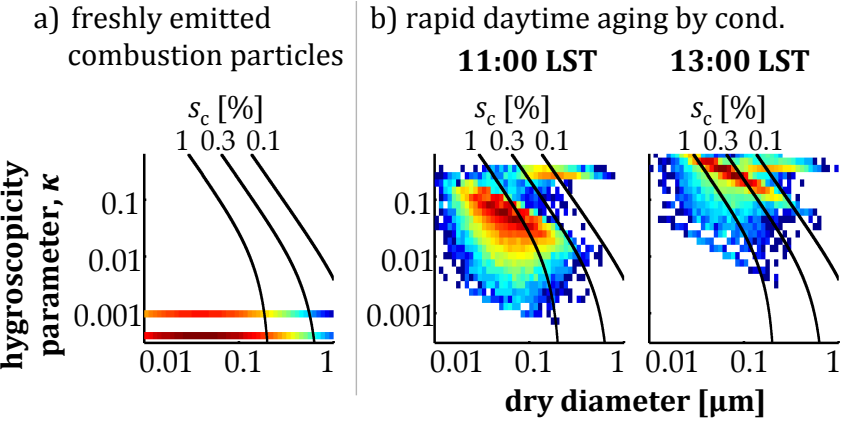

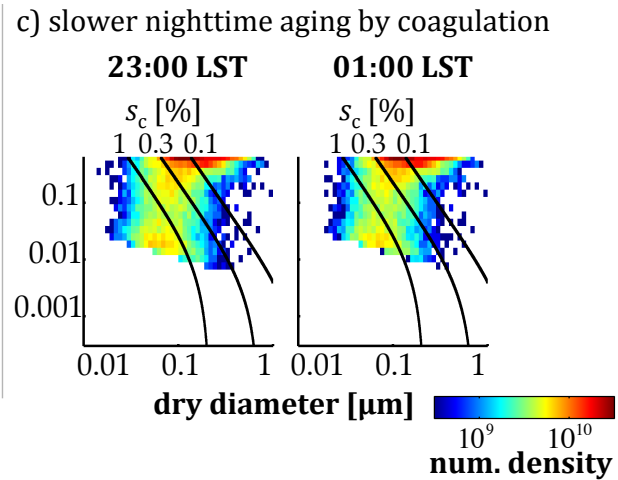

Figure 1. Two-dimensional probability density distribution shows changes in particle properties. As particles increase in size (horizontal axis) and hygroscopicity (vertical axis), they are able to activate at lower critical supersaturation thresholds (superimposed lines). (a) Freshly emitted particles are hydrophobic, with $\kappa=3 \times 10^{-4}$ and $\kappa=8 \times 10^{-4}$ for diesel and gasoline, respectively. (b) During the daytime, particles age rapidly by condensation of semivolatile substances that are produced through photochemical reactions. (c) At night, condensation aging is slow and particles age only by coagulation.

ber balances for all processes affecting aging, are given in Riemer et al. (2010).

The temporal evolution of the timescale is shown for the baseline scenario in Fig. $2 \mathrm{a}$ at $s=0.1 \%, s=0.3 \%$, and $s=1 \%$. The aging timescale is a simple metric for quantifying the effects of changes in per-particle size and hygroscopicity that are shown in Fig. 1, and the gray shading in Fig. 2a corresponds to the time periods shown in Fig. 1. Particles must become highly hygroscopic to activate into cloud droplets at low $s$ (e.g., $s=0.1 \%$ ) but require less processing to become CCN at higher values of $s$ (e.g., $s=1 \%$ ), so the aging timescale tends to be shorter for higher values of $s$.

Any particle that transitions from fresh at $t$ to aged at $t+\Delta t$ does so either by coagulation with a large, hygroscopic particle or by accumulating sufficient condensing material to become hygroscopic. The overall aging timescale $\tau_{\text {aging }}$ can be represented as the combination of separate timescales for aging by condensation $\tau_{\text {cond }}$ and by coagulation $\tau_{\text {coag }}$ :

$\frac{1}{\tau_{\text {aging }}(t, s)}=\frac{1}{\tau_{\text {cond }}(t, s)}+\frac{1}{\tau_{\text {coag }}(t, s)}$.

The contribution of condensation and coagulation to the overall aging timescale is shown by separate timescales for aging by condensation ( $\left.\tau_{\text {cond }}\right)$ and coagulation $\left(\tau_{\text {coag }}\right)$ at $s=0.3 \%$ in Fig. 2b. We computed the coagulation and condensation aging timescales by counting the number of particles that transition from fresh to aged after participating in a coagulation event, $\Delta N_{\mathrm{f} \rightarrow \mathrm{a} \text {,coag }}$, or that age only by condensation, $\Delta N_{\mathrm{f} \rightarrow \text { a,cond. Then, we applied Equation } 4 \text { to }}$ find the corresponding condensation and coagulation aging timescales. Figure $2 \mathrm{~b}$ shows that the overall aging timescale is shortest during the day (e.g., $1 \mathrm{~h}$ at $s=0.3 \%$ ), due to rapid condensation of semivolatile substances, and considerably longer at night (e.g., $24 \mathrm{~h}$ at $s=0.3 \%$ ), when coagulation a)

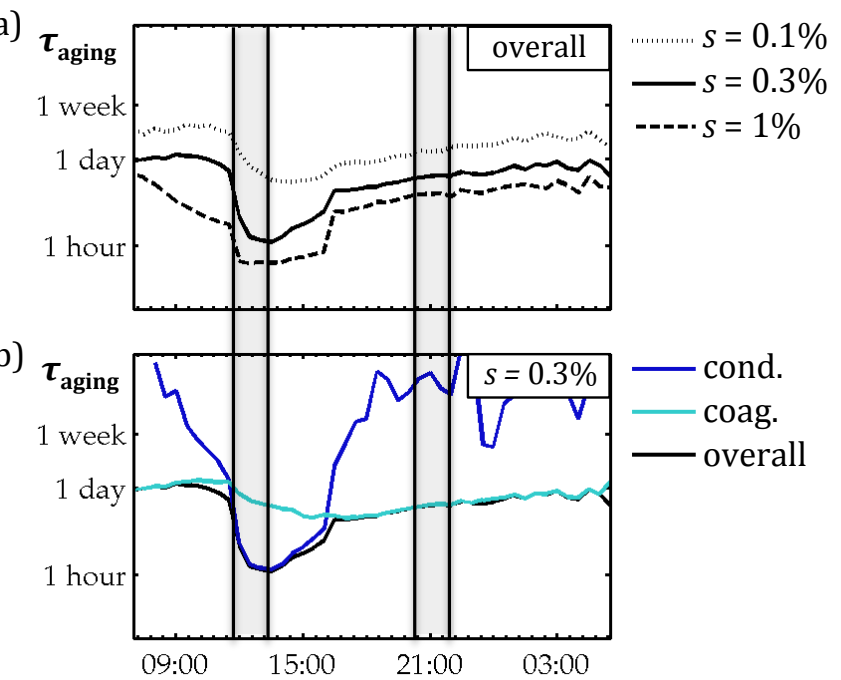

Figure 2. For a single scenario, overall aging timescale for $s=$ $0.1 \%, s=0.3 \%$, and $s=1 \%$ in panel (a) and the overall, condensation, and coagulation aging timescales for $s=0.3 \%$ in panel (b). The shaded regions show how the value of the aging timescale reflects changes in per-particle characteristics, which correspond to Fig. 1. Short aging timescales correspond to rapid increases in particle size and hygroscopicity (Fig. 1b), and long aging timescales correspond to slow changes in particle properties (Fig. 1c)

is the dominant aging mechanism. The temporal evolution of $\tau_{\text {aging }}$ and $\tau_{\text {cond }}$ are shown for multiple supersaturation levels in Riemer et al. (2010).

\section{Ensemble of particle-resolved model scenarios}

The aging timescales shown in Fig. 2 are limited to only one scenario, and aging rates vary with local conditions. For example, the number concentration and size distribution of 
Table 3. Hygroscopicity parameter assigned to aerosol species

\begin{tabular}{lll}
\hline Aerosol species & $\kappa_{i}$ & Citation \\
\hline $\mathrm{NO}_{3}$ & 0.65 & Clegg et al. (1998); Svenningsson et al. (2006); Petters and Kreidenweis (2007) \\
$\mathrm{SO}_{4}$ & 0.65 & Clegg et al. (1998); Svenningsson et al. (2006); Petters and Kreidenweis (2007) \\
$\mathrm{NH}_{4}$ & 0.65 & Clegg et al. (1998); Svenningsson et al. (2006); Petters and Kreidenweis (2007) \\
$\mathrm{SOA}$ & 0.1 & Prenni et al. (2007) \\
$\mathrm{BC}$ & 0 & Petters et al. (2006) \\
POA & 0.001 & Petters et al. (2006) \\
\hline
\end{tabular}
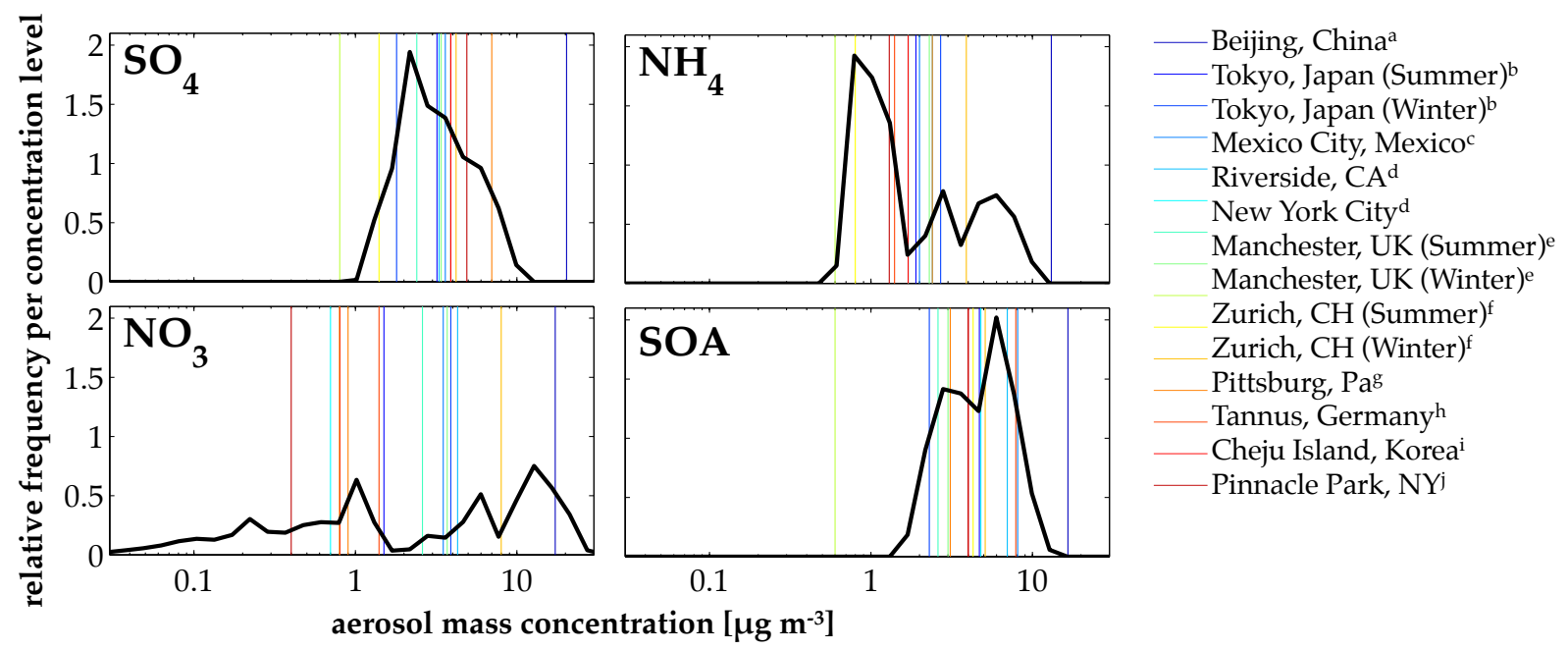

Figure 3. Probability density function of aerosol mass species in simulations (black line in each graph) show that model cases represent variation in atmospheric conditions from ambient observations (vertical colored lines). Probability density functions include all output time steps in the full ensemble of sensitivity simulations. References for observations corresponding to each line: (a) Sun et al. (2010), (b) Takegawa et al. (2005, 2006), (c) Aiken et al. (2009), (d) DeCarlo et al. (2008); Docherty et al. (2008); Cubison et al. (2006), (e) Drewnick et al. (2004a, b), (f) Weimer et al. (2006), (g) Allan et al. (2003a, b), (h) Lanz et al. (2007), (i) Zhang et al. (2004, 2005a, b, c, 2007), (j) Dusek et al. (2006); Hings et al. (2007), (k) Topping et al. (2004), (1) Bae et al. (2006).

background particles affect coagulation rates and, thereby, the coagulation aging timescale. In order to identify the set of independent variables that best explain variance in BC's aging timescale under a range of atmospheric conditions, we simulated aerosol dynamics in a series of plume scenarios and extracted aging timescales for each scenario. As we will show, the environmental properties that affect aerosol dynamics varied diurnally and differed between scenarios, causing the aging timescale to range from less than an hour (a large portion of particles age per time interval) to longer than a week (few particles age per time interval).

The input parameters that were varied between the scenarios are shown in Table 4. These input parameters were selected to produce a range of environmental conditions, consistent with observations described by Jimenez et al. (2009) and references therein. Simulations were performed using every combination of input parameters given in Table 4, leading to a total of 288 scenarios. In each scenario, aerosol concentrations and particle characteristics varied throughout the $24 \mathrm{~h}$ simulation. The conclusions in this study are based on these simulations of urban air masses.

Figure 3 shows the distribution of aerosol mass concentration for selected aerosol species for all scenarios simulated with PartMC-MOSAIC (black lines) and corresponding ambient observations compiled by Jimenez et al. (2009) (vertical colored lines). The range of conditions simulated in the ensemble of scenarios is representative of the distribution in concentrations observed in these urban areas. The distribution in the number concentration of all particles and of BC-containing particles are shown in Fig. $4 \mathrm{a}$ and b, respectively. The size and composition of BC-containing particles also varied over the course of an individual simulation, as we showed in Fig. 1. Variations in the geometric mean diameter and in the geometric mean hygroscopicity parameter of BC-containing particles across all simulations are shown in Fig. $4 \mathrm{c}$ and d, respectively. Figures 3 and 4 were constructed from data at $10 \mathrm{~min}$ intervals in each of the 288 simulations, corresponding to 41000 time steps. 
Table 4. Input parameters varied in the ensemble of sensitivity simulations. Scenarios corresponding to the baseline conditions are indicated in bold. All combinations of scenarios were included in the full ensemble of 288 simulations.

\begin{tabular}{|c|c|c|}
\hline Input parameter & Scenario name & Values assigned \\
\hline \multirow[t]{4}{*}{ Gas-phase emissions } & $\mathbf{G}_{1}$ & baseline gas emissions \\
\hline & $\mathrm{G}_{2}$ & increase $\mathrm{SO}_{2}$ emissions by $200 \%$ and turn off $\mathrm{NH}_{3}$ emissions \\
\hline & $\mathrm{G}_{3}$ & increase $\mathrm{SO}_{2}$ emissions by $300 \%$ \\
\hline & $\mathrm{G}_{4}$ & increase SOA precursor emissions by $200 \%$ and turn off $\mathrm{NH}_{3}$ emissions \\
\hline \multirow{3}{*}{ Black carbon emissions } & & increase selected SOA precursors by $100 \%$ \\
\hline & $\mathbf{B C}_{1}$ & baseline diesel and gasoline emissions \\
\hline & $\mathrm{BC}_{2}$ & increase diesel and gasoline emissions by a factor of 5 \\
\hline \multirow{3}{*}{ Background aerosol } & $\mathrm{BC}_{3}$ & increase diesel and gasoline emissions by a factor of 10 \\
\hline & $\mathbf{B G}_{1}$ & baseline background aerosol concentration \\
\hline & $\mathrm{BG}_{2}$ & decrease background aerosol concentration by $45 \%$ \\
\hline \multirow[t]{2}{*}{ Relative humidity } & $\mathbf{R H}_{1}$ & $95 \%$ \\
\hline & $\mathrm{RH}_{2}$ & $50 \%$ \\
\hline \multirow{6}{*}{ Meteorological conditions } & $\mathbf{M}_{1}$ & $5^{\circ} \mathrm{N}, 19$ July, $303 \mathrm{~K}$ \\
\hline & $\mathrm{M}_{2}$ & $5^{\circ} \mathrm{N}, 5$ January, $303 \mathrm{~K}$ \\
\hline & $\mathrm{M}_{3}$ & $40^{\circ} \mathrm{N}, 19 \mathrm{July}, 298 \mathrm{~K}$ \\
\hline & $\mathrm{M}_{4}$ & $40^{\circ} \mathrm{N}, 5$ January, $275 \mathrm{~K}$ \\
\hline & $\mathrm{M}_{5}$ & $60^{\circ} \mathrm{N}, 19 \mathrm{July}, 293 \mathrm{~K}$ \\
\hline & $\mathrm{M}_{6}$ & $60^{\circ} \mathrm{N}, 5$ January, $263 \mathrm{~K}$ \\
\hline
\end{tabular}

Variance in the aging timescale is shown by the probability density distribution in Fig. 5, which includes each $10 \mathrm{~min}$ time interval in each of the 288 simulations. Distributions are shown for timescales computed at $s=0.1 \%, s=0.3 \%$, and $s=1 \%$. The supersaturation threshold $s$ specifies the degree of change in particle properties required to classify a particle as aged, and timescales tend to decrease as $s$ increases. In the following sections, we show that most of the variance in black carbon's aging timescale at a specific $s$ is explained by only a few key variables.

\section{Nonparametric regression analysis to quantify explained variance}

Black carbon's aging timescale ranges from minutes to weeks (Fig. 5), depending on local conditions and characteristics of BC-containing particles. We evaluated how well different combinations of independent variables explain variance in black carbon's aging timescale by comparing predictions of aging timescales from nonparametric regression with exact aging timescales from PartMC-MOSAIC. A nonparametric regression was chosen, rather than a parametric regression, because we do not know a priori the shape of the predictor surface.

The procedure in applying a nonparametric regression is as follows: (1) select a set of candidate independent variables to test; (2) use most (90\% of simulations) of the data as the training set to find the expected value of the aging timescale as a function of the independent variables, as will be explained below; and (3) evaluate this expected aging timescale using the rest of the data (10\% of simulations), called the testing set. The timescale from the regression is assessed by how well it predicts the values of the aging timescale in the testing set, represented by $R^{2}$. The purpose of this exploration is to find the independent variables that explain most of the variance in the aging timescale, indicated by the largest value of $R^{2}$. To ensure that our conclusions did not depend on the choice of scenarios, we repeated the analysis several times with randomly chosen testing and training sets and verified that $R^{2}$ was insensitive to the specific choice of testing and training sets.

\subsection{Kernel density regression applied to particle-resolved model data}

Figure 6 shows how the regression analysis is applied in this study. For all times in all simulations in the testing set, a particle that is fresh at time $t$ may age between $t$ and some later time $t+\Delta t$ or it may remain fresh over that time period. Because these two events are mutually exclusive, this aging behavior in PartMC-MOSAIC may be represented by a binary variable $Y_{\text {age, } j}(t, t+\Delta t, s)$, where $Y_{\text {age, } j}=1$ if the particle ages between $t$ and $t+\Delta t$ and $Y_{\text {age, } j}=0$ if it remains fresh. The aging timescale at each model time step can then be computed from the average of $Y_{\mathrm{age}, j}$ across all fresh BC- 


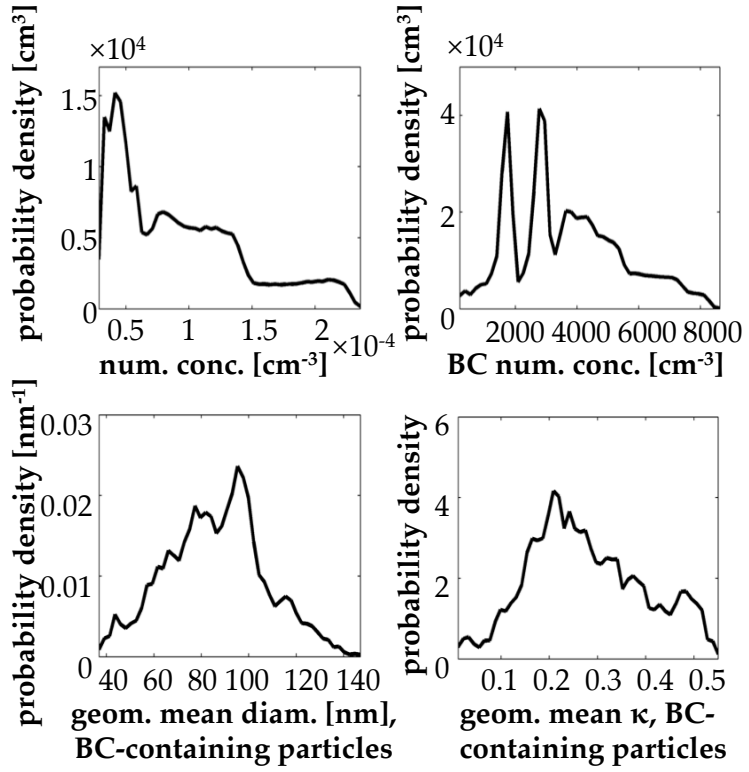

Figure 4. Probability density function of (a) total aerosol number concentration, (b) total number concentration of BC-containing particles, (c) geometric mean diameter of BC-containing particles, and (d) geometric mean hygroscopicity parameter of BC-containing particles.

containing particles:

$\tau_{\text {aging }}(t, s)=\Delta t \frac{N_{\mathrm{p}, \text { fresh }}}{\sum_{i=1}^{N_{\mathrm{p}, \text { fresh }}} Y_{\text {age }, j}(t, t+\Delta t)}$,

which is equivalent to Eq. (4), computed from $N_{\text {p,fresh }}$ individual particles over a specific model time step.

Alternatively, the expected probability that a fresh particle will age, given its characteristics or the aging conditions that it experiences, can be estimated from a nonparametric regression. We applied the kernel density regression introduced by Watson (1964) and Nadaraya (1964). The expected value of $Y_{\text {age }, j}$ for a specific particle in the testing set is predicted using the kernel density regression, using information about the candidate variable $x_{j}$ only. The candidate variable $x_{j}$ may be a particle-level characteristic, which varies between particles and, for a specific particle, varies over time (e.g., particle wet diameter). The candidate variable $x_{i}$ may also be a characteristic of the environment, which varies over time but, at a specific time, is the same for all particles (e.g., aerosol number concentration). All candidate variables explored in this study are outlined in Table 5. In this section, we show how the nonparametric regression can be applied to evaluate variance explained by a single candidate variable at a time. Later, we show how this analysis can be extended to evaluate combinations of independent variables.

At each time step in each simulation of the testing set, the expected value of $Y_{\text {age }}(t, t+\Delta t, s)$ for each particle was computed as a weighted average of $Y_{\mathrm{age}, i}(t, t+\Delta t, s)$ for

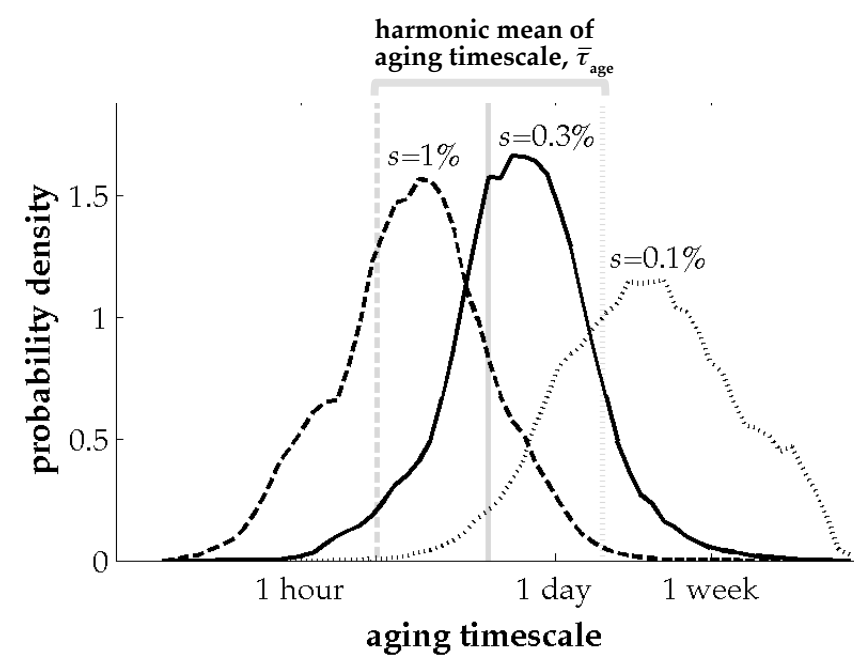

Figure 5. Probability density function of aging timescales for the full ensemble of sensitivity simulations, computed at three environmental supersaturation levels: $s=0.1 \%, s=0.3 \%$, and $s=1 \%$.

millions of individual particles in the training set. Values for $Y_{\text {age }, i}(t, t+\Delta t, s)$ in the training set are weighted according to the kernel function $K_{h}\left(x-x_{i}\right)$, where $x$ is the independent variable of interest. The expected value of $Y_{\text {age }}(t, t+\Delta t, s)$ is given by

$E\left[Y_{\text {age }} \mid x_{j}(t), \Delta t, s\right]=\frac{\sum_{i=1}^{N_{\mathrm{p}, \text { train }}} K_{h}\left(x_{j}(t)-x_{i}\right) Y_{\mathrm{age}, i}}{\sum_{i=1}^{N_{\mathrm{p}, \text { train }}} K_{h}\left(x_{j}(t)-x_{i}\right)}$,

where $x_{i}$ is the value of the independent variable for each particle in the training set, $x_{j}$ is the value of the independent variable for the target particle in the testing set, and $N_{\mathrm{p} \text {,train }}$ is all particles in the training set, including all time steps in all simulations.

Analogous to Eq. (6), the expected value of the aging timescale at a specific model time step, $\hat{\tau}_{\text {aging }}(t, s)$, is then computed as the average of $E\left[Y_{\text {age }} \mid x_{j}(t), \Delta t, s\right]$ across all fresh $\mathrm{BC}$-containing particles:

$\hat{\tau}_{\text {aging }}(t, s)=\Delta t \frac{N_{\mathrm{p}, \text { fresh }}}{\sum_{j=1}^{N_{\mathrm{p}, \text { fresh }}} E\left[Y_{\text {age }} \mid x_{j}(t), \Delta t, s\right]}$.

In Sect. 4.2, we provide further explanation on the inclusion of particle-level characteristics in the prediction of $\hat{\tau}_{\text {aging. }}$.

In this study we used a Gaussian kernel function with standard deviation $h$ :

$K_{h}\left(x_{j}(t)-x_{i}\right)=\frac{1}{\sqrt{2 \pi} h} \exp \left(-\frac{\left(x_{j}(t)-x_{i}\right)^{2}}{2 h^{2}}\right)$.

The kernel function $K_{h}\left(x_{j}(t)-x_{i}\right)$ defines the weight applied to each model timescale $\tau_{\text {age,i }}$ to compute the expected 
Table 5. Candidate variables included in the regression analysis.

\begin{tabular}{lll}
\hline Symbol & Description & Type \\
\hline$D$ & wet diameter & particle level \\
$D_{\text {dry }}$ & dry diameter & particle level \\
$\kappa$ & hygroscopicity parameter & particle level \\
$\varepsilon_{\text {BC }}$ & mass fraction BC & particle level \\
$\varepsilon_{\text {SOA }}$ & mass fraction SOA & particle level \\
$\varepsilon_{\text {inorg }}$ & mass fraction inorganic aerosol & particle level \\
$N$ & overall aerosol number concentration & population level \\
$A_{\text {wet }}$ & aerosol surface area concentration & population level \\
$\dot{V}_{\text {cond }}$ & secondary aerosol formation rate, volume & population level \\
$\dot{f}_{\text {cond }}$ & secondary aerosol flux, $\dot{V}_{\text {cond }} / A_{\text {wet }}$ & population level \\
$\dot{m}_{\text {cond }}$ & secondary aerosol formation rate, mass & population level \\
$\kappa_{\text {cond }}$ & hygroscopicity parameter of secondary aerosol & population level \\
$N_{\text {CCN }}$ & number concentration of CCN-active particles & population level \\
$N_{\text {large }}$ & no. conc. of particles with $D>100$ nm & population level \\
$N_{\text {CCN,large }}$ & no. conc. of CCN-active particles with $D>100 \mathrm{~nm}$ & population level \\
\hline
\end{tabular}

timescale $\hat{\tau}_{\text {age }}$, such that timescales for conditions similar to the conditions of the target point are weighted most heavily in the regression. The regression function predicted by the kernel regression depends on the prescribed value for $h$, where larger $h$ results in smoother regression functions. We applied Silverman's rule of thumb to select the value for $h$ (Silverman, 1986), such that $h$ depends on the number of independent variables, the standard deviation of each independent variable, and the total number of data points in the testing set.

If the timescale depends only on the candidate variable $x$, the expected aging timescale $\hat{\tau}_{\text {aging, } j}$ will accurately represent the actual aging timescale $\tau_{\text {aging, } j}$, assuming a suitable kernel bandwidth $h$ is applied in the kernel regression. Aging rates scale with the inverse of the aging timescale, so we quantified the variance explained by the regression function, $R^{2}$, in terms of $1 / \tau_{\text {aging: }}$ :

$$
R^{2}(s)=1-\frac{\sum_{j=1}^{n_{\text {test }}} N_{\text {fresh }, j}(s)\left(\frac{1}{\hat{\tau}_{\text {aging }, j}(s)}-\frac{1}{\tau_{\text {aging }, j}(s)}\right)^{2}}{\sum_{j=1}^{n_{\text {test }}} N_{\text {fresh }, j}(s)\left(\frac{1}{\hat{\tau}_{\text {aging }, j}(s)}-\frac{1}{\bar{\tau}_{\text {aging }}(s)}\right)^{2}},
$$

where $\tau_{\text {aging, } j}$ is the timescale from PartMC-MOSAIC for each data point in the testing set, $\hat{\tau}_{\text {aging, } j}$ is the expected timescale from the regression for each data point in the testing set, $\bar{\tau}_{\text {aging }}$ is the harmonic mean of the aging timescales across all data points in the testing set, and $N_{\text {test }}$ is the number of data points in the testing set, where the data points include all time steps in all scenarios.

\subsection{Inclusion of particle-level variables in the kernel regression}

To illustrate our approach for including particle-level variables, we demonstrate the regression procedure using the wet diameter as the independent variable $x$. The resulting regression surface is a size-dependent timescale, which gives insight into the importance of aging processes as a function of particle wet diameter. For a given set of environmental conditions, some particles are more likely to age than others, and we find that a particles' tendency to age depends on their characteristics just prior to the aging period. We evaluated how aging rates vary with a number of per-particle characteristics, such as particles' diameter at emission, their dry diameter at the time when aging is evaluated, or their hygroscopicity parameter when aging is evaluated. We found that for given environmental conditions, per-particle aging rates were most correlated with the wet diameter of fresh (CCN-inactive) particles; that is, values of $R^{2}$ were greatest for regression functions that included the time-varying wet size distribution of fresh BC-containing particles.

It is therefore useful to introduce a size-resolved aging timescale that accounts for differences in aging rates between particles of different sizes. Size-resolved aging timescales were computed at each time $t$ and supersaturation $s$ using the kernel regression described in Sect. 4.1. The expected value of $Y_{\text {age }}$ for a particle in the testing set with wet diameter $D_{j}(t)$ was computed as the weighted average of $Y_{\mathrm{age}, i}$ for particles the training set $i=1, \ldots, N_{\mathrm{p} \text {,train }}$, computed at a specific $t$ and $s$ :

$$
E\left[Y_{\mathrm{age}} \mid D_{j}(t), \Delta t, s\right]=\frac{\sum_{i=1}^{N_{\mathrm{p}, \text { train }}} K_{h_{D}}\left(D_{j}(t)-D_{i}\right) Y_{\mathrm{age}, i}}{\sum_{i=1}^{N_{\mathrm{p}, \text { train }}} K_{h_{D}}\left(D_{j}(t)-D_{i}\right)},
$$




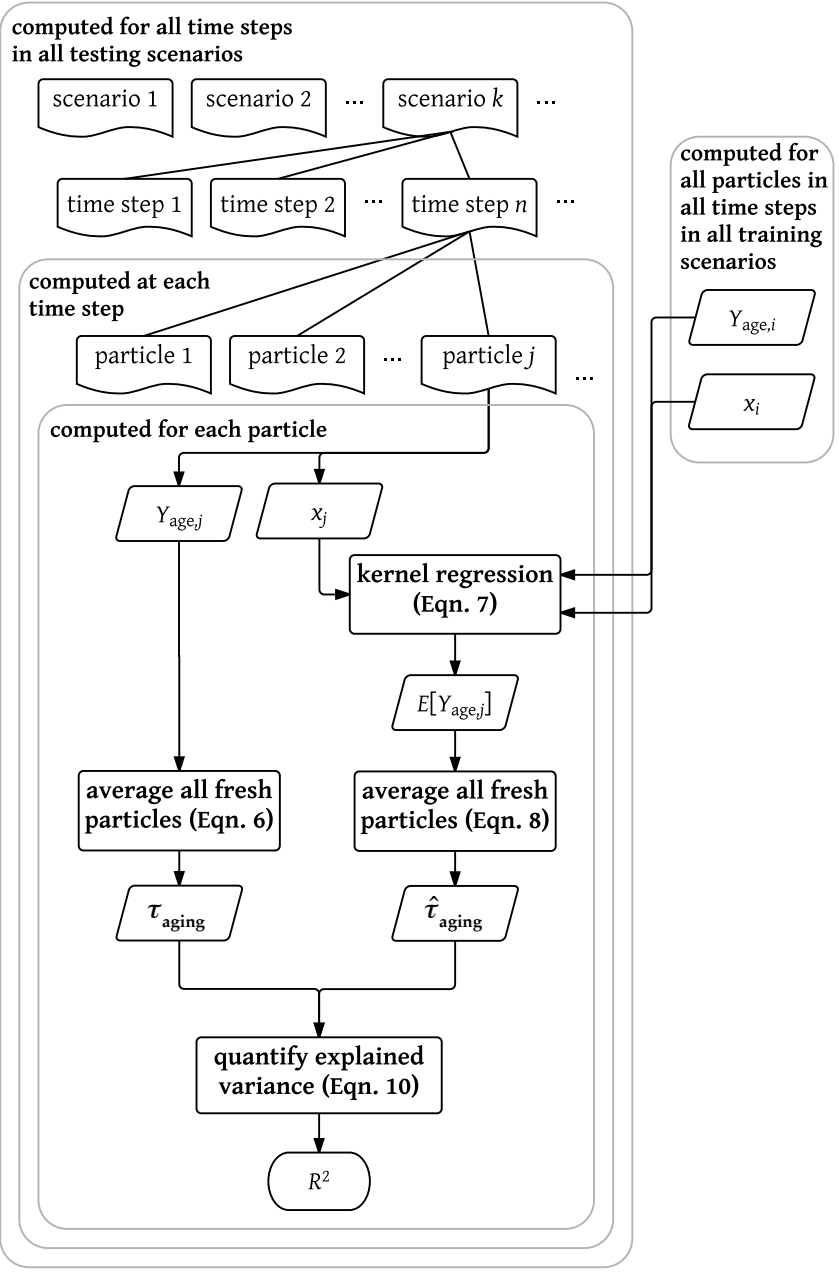

Figure 6. Procedure for applying kernel regression to predict black carbon's aging timescale and quantifying the portion of variance explained by that prediction, shown for a hypothetic input variable $x$.

where the kernel weighting function $K_{h}\left(D_{j}(t)-D_{i}\right)$ is Gaussian (Eq. 9), such that fresh particles with $D_{i}$ similar to the target diameter $D_{j}$ are weighted most heavily in the regression. The size-resolved aging timescale can also be defined for a continuous size distribution of fresh particles $n_{\text {fresh }}(t, D, s)$. Similar to Eq. (8), the size-resolved aging timescale, $\tau_{\text {aging }}(D)$, is computed as a function of $E\left[Y_{\text {age }} \mid D\right]$ and the time step $\Delta t$ :

$\hat{\tau}_{\text {aging }}(t, D, s)=\frac{\Delta t}{E\left[Y_{\text {age }} \mid D(t), \Delta t, s\right]}$.

For a particle-resolved population of fresh particles $j=$ $1, \ldots, N_{\mathrm{p}, \text { fresh }}$, where each particle has a unique wet diameter $D_{j}$, the bulk, population-level aging timescale can be estimated as the average of $E\left[Y_{\text {age }} \mid D_{j}(t), \Delta t, s\right]$ across all

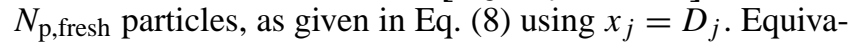
lently, the population-level aging timescale can be computed through the average of the continuous size-resolved aging timescale $\hat{\tau}_{\text {aging }}(D, t, s)$, weighted by the size distribution of fresh particles $n_{\text {fresh }}(D, t, s)$ :

$$
\hat{\tau}_{\text {aging }}(t, s)^{-1}=\frac{\int_{0}^{\infty} \hat{\tau}_{\text {aging }}(t, D, s)^{-1} n_{\text {fresh }}(t, D, s) \mathrm{d} D}{\int_{0}^{\infty} n_{\text {fresh }}(t, D, s) \mathrm{d} D} .
$$

By this relationship, the bulk aging timescale under a specific set of environmental conditions also varies with the size distribution of CCN-inactive (fresh) BC.

The temporal evolution of the size-resolved aging timescale is shown for the baseline scenario in the middle column of Fig. 7 for $s=0.3 \%$. The contributions of coagulation (Fig. 7b) and condensation (Fig. 7c) to the overall aging timescale (Fig. 7a) are shown by the separate size-resolved timescales for each process. The dominant mechanism driving the aging timescale depends on the time of day and the particle size.

A comparison between Fig. 7a and c shows that condensation was the dominant process driving diurnal variation in the size-resolved aging timescale. This diurnal pattern in condensation aging conditions is reflected in the bulk aging timescale shown in Fig. 2. The bulk condensation aging timescale was shorter than $4 \mathrm{~h}$ during the day for this scenario, and this was the dominant process affecting aging rates at this time. However, Fig. 7c shows that these rapid transitions from $\mathrm{CCN}$-inactive to $\mathrm{CCN}$-active occurred only for the largest $(D>50 \mathrm{~nm})$ fresh particles, although condensation also caused an increase in $D$ for smaller fresh particles. The coagulation aging timescale, on the other hand, was short for the smallest fresh particles and varied only slightly over the course of the simulation.

\subsection{Combining particle-level and population-level variables in kernel regression}

In this study, we performed a series of multivariate kernel regressions to identify the combination of independent variables that best explain variance in black carbon's aging timescale. In many cases, we extracted aging timescales that depend both on characteristics of individual particles, such as $D$, and on properties of entire particle populations or the environment, such as the overall aerosol number concentration $N$. One advantage of this approach is that both particle-level variables and population-level variables can be included in the prediction of $Y_{\mathrm{age}, j}$. For example, the expected value of $Y_{\text {age, } j}$ for a particle with diameter $D_{j}$ that is exposed to an aerosol number concentration $N_{j}$ is computed with the bi- 


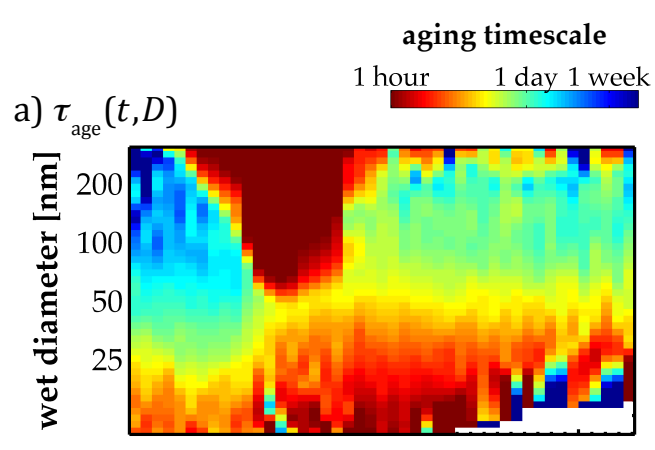

b) $\tau_{\text {coag }}(t, D)$

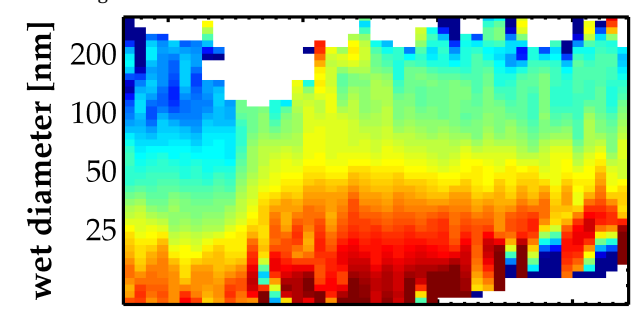

c) $\tau_{\text {cond }}(t, D)$

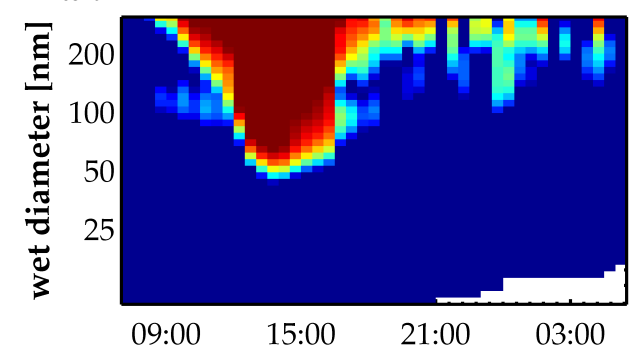

Figure 7. For baseline scenario, (a) overall size-dependent aging timescale, (b) condensation aging timescale, and (c) coagulation aging timescale. Values are shown for $s=0.3 \%$.

variate kernel regression:

$$
\begin{aligned}
& E\left[Y_{\mathrm{age}} \mid D_{j}, N_{j}\right]= \\
& \sum_{i=1}^{N_{\mathrm{p}, \text { train }}} K_{h_{D}}\left(D_{j}(t)-D_{i}\right) K_{h_{f}}\left(N_{j}(t)-N_{i}\right) Y_{\mathrm{age}, i} \\
& \sum_{i=1}^{N_{\mathrm{p}, \text { train }}} K_{h_{D}}\left(D_{j}(t)-D_{i}\right) K_{h_{f}}\left(N_{j}(t)-N_{i}\right)
\end{aligned}
$$

The overall aging timescale for a particular size distribution exposed to a specific number concentration is the computed as the sum across individual particles (Eq. 8) or, equivalently, by integrating over the size distribution (Eq. 13). Equation 14 can easily be generalized to three or more independent variables.

\section{Independent variables that best explain variance in aging timescales}

We found that most variance in the aging timescale is explained by only a few independent variables. Explained variance $R^{2}$ is shown for different combinations of independent variables as a function of the criterion supersaturation. For all supersaturation levels, $90 \%$ of variance in the coagulation aging timescale (Fig. 8a) was explained by regression predictions that included the size distribution of fresh BCcontaining particles $\left(n_{\text {fresh }}(D)\right)$ and the number concentration of large, $\mathrm{CCN}$-active particles $\left(N_{\mathrm{CCN} \text {,large }}\right)$. Three variables were needed to explain $85 \%$ of variance in the condensation aging timescale (Fig. 8b): the size distribution of fresh BC-containing particles $\left(n_{\text {fresh }}(D)\right)$; the flux of secondary aerosol $\left(\dot{f}_{\text {cond }}\right)$, defined as the volume condensation rate of semivolatile substances per particle surface area density; and the effective hygroscopicity parameter of secondary aerosol ( $\left.\kappa_{\text {cond }}\right)$, where $\kappa_{\text {cond }}$ is the volume-weighted average of $\kappa$ for condensing semivolatile species. The size distribution of fresh $\mathrm{BC}$ was included in each case by determining a regression for the size-resolved aging timescale before computing the bulk aging timescale according to Equation 13. Only 10$15 \%$ of variance remains unexplained, indicating that variables other than $n_{\text {fresh }}(D), \dot{f}_{\text {cond }}, \kappa_{\text {cond }}$, and $N_{\mathrm{CCN} \text {,large }}$ also weakly affect the value of the aging timescale.

\subsection{Variance explained by different combinations of independent variables}

Figure 8 shows the explained variance $R^{2}$ as a function of $s$ for the independent variables that best explain variance in the coagulation and condensation aging timescales. Approximately $90 \%$ of variance in the coagulation aging timescale was explained by regressions in terms of $n_{\text {fresh }}(D)$ and $N_{\mathrm{CCN} \text {,large }}$ (black line of Fig. 8a). Brownian coagulation events are most likely to occur between large and small particles, so the coagulation aging timescale decreases when there are more particles that are $\mathrm{CCN}$-active and are also large enough to be good coagulation partners. The smallest fresh particles are likely to coagulate with large background particles, where we found the threshold for "large" to be $D>100 \mathrm{~nm}$ by identifying the threshold that resulted in the highest $R^{2}$. A regression computed in terms of the number concentration of large particles (green line of Fig. 8a), rather than the number concentration of large and CCN-active particles, gave $R^{2} \approx 85 \%$ at high supersaturation thresholds ( $s>0.8 \%$ ) but $R^{2}<10 \%$ at low supersaturation thresholds $(s<0.1 \%)$. This is because not all particles with $D>100 \mathrm{~nm}$ are CCN-active at $s=0.1 \%$, but nearly all particles that are CCN-active at this low $s$ have $D>100 \mathrm{~nm}$. On the other hand, if the independent variable was the number concentration of $\mathrm{CCN}$-active particles (blue line of Fig. 8a), rather than the number concentration of large and $\mathrm{CCN}$ active particles, $R^{2} \approx 90 \%$ for timescales at low supersatura- 
a) coagulation aging timescale

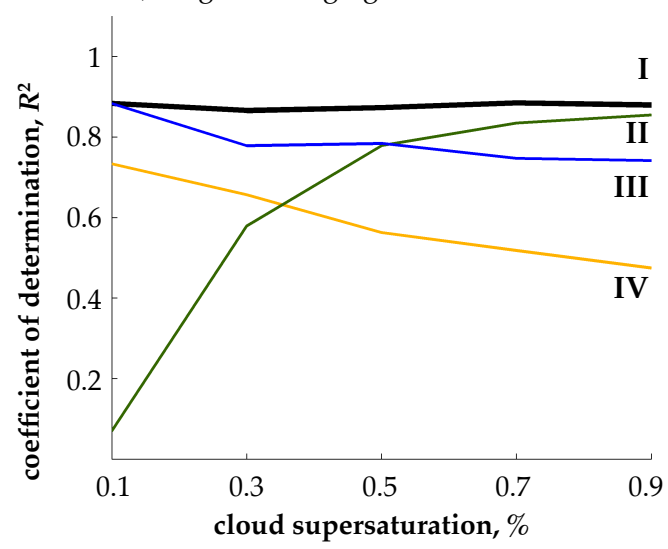

b) condensation aging timescale

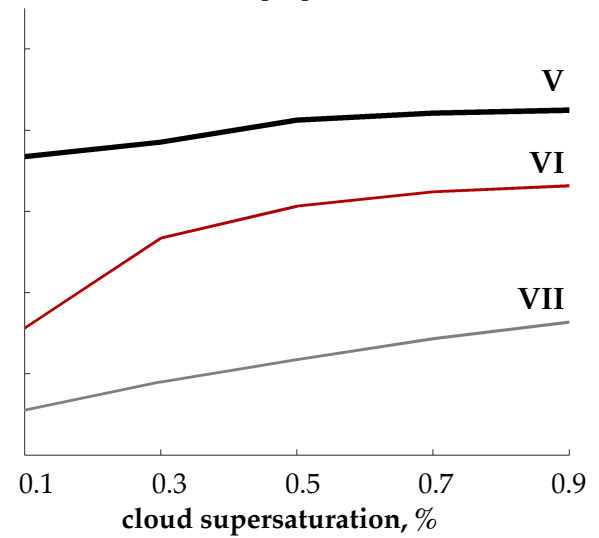

Figure 8. Coefficient of determination $R^{2}$ for (a) coagulation and (b) condensation timescales as a function of supersaturation for selected combinations of independent variables, where the combination of variables that explain most of the variance are shown by the black lines in each graph. Regression analyses on the coagulation aging timescales are shown for four combinations of independent variables: (I) including wet diameter, $D$, of fresh BC-containing particles and the number concentration of large $(D>100 \mathrm{~nm})$, CCN-active particles, $N_{\mathrm{CCN} \text {,large }}$; (II) including $D$ of fresh BC-containing particles and the number concentration of large particles, $N_{\text {large }}$, rather than $N_{\mathrm{CCN} \text {,large }}$; (III) including $D$ of fresh particles and the number concentration of $\mathrm{CCN}$-active particles, $N_{\mathrm{CCN}}$, rather than $N_{\mathrm{CCN} \text {, large }}$; and (IV) including $N_{\mathrm{CCN} \text {,large }}$ but without including $D$ of fresh BC-containing particles. Regression analyses on the condensation aging timescale are shown for three combinations of independent variables: $(\mathrm{V})$ including secondary aerosol flux, $\dot{f}_{\text {cond }}$, the hygroscopicity of secondary aerosol, $\kappa_{\text {cond }}$, and $D$ of fresh BC-containing particles; (VI) including $\dot{f}_{\text {cond }}$ and $\kappa_{\text {cond }}$ but without including $D$ of fresh BC-containing particles; and (VII) including $\dot{f}_{\text {cond }}$ and $D$ of fresh BC-containing particles but without including $\kappa_{\text {cond }}$. For all $s$, approximately $90 \%$ of variance in the coagulation aging timescale is explained by two independent variables (black line in panel (a)), and $80 \%$ of variance in the condensation aging timescale is explained by three independent variables (black line in panel (b)).
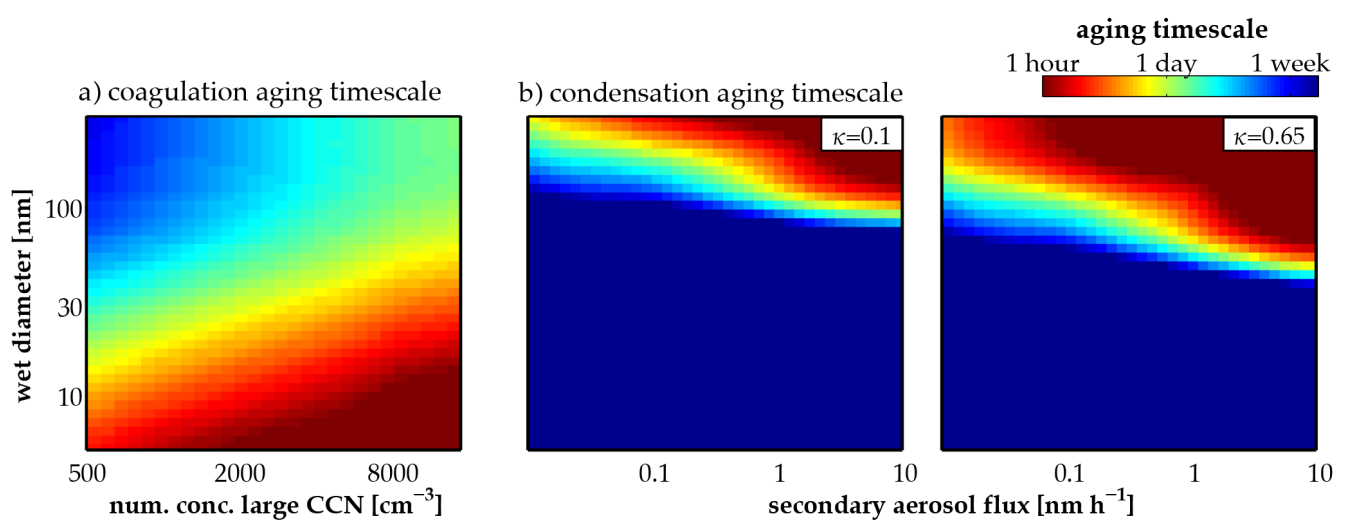

Figure 9. Coagulation aging timescale as a function of wet diameter and number of large, CCN-active particles (a) and condensation aging timescale as a function of wet diameter, secondary aerosol flux, and hygroscopicity of secondary aerosol (b). Results are shown for a threshold supersaturation $s$ of $0.3 \%$.

tion thresholds $(s<0.1 \%)$ and $R^{2} \approx 70 \%$ at high supersaturation thresholds $(s>0.8 \%)$. Only by considering the number concentration of particles that are both $\mathrm{CCN}$-active and

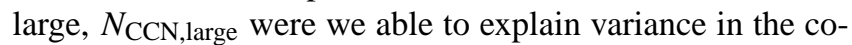
agulation aging timescale at all supersaturation levels. If the size distribution of fresh $\mathrm{BC}$ was neglected, $R^{2}$ ranged from 40 to $60 \%$, depending on the supersaturation threshold (yellow line of Fig. 8a).

While the expected aging timescale computed in terms of $n_{\text {fresh }}(D), \dot{f}_{\text {cond }}$, and $\kappa_{\text {cond }}$ (black line in Fig. $8 \mathrm{~b}$ ) ex- plained greater than $80 \%$ of variance in the condensation aging timescale, $R^{2}$ was less than $60 \%$ for regressions that did not include $n_{\text {fresh }}(D)$ (red line). Only 10-30\% of variance was explained if $\kappa_{\text {cond }}$ was not included in the regression (grey line). If $\dot{f}_{\text {cond }}$ was not included, $R^{2} \approx 0 \%$ for all $s$, regardless of the other variables included in the regression (not shown). This suggests, not surprisingly, that the condensation rate is the key variable driving aging by condensation, but the condensation aging timescale also depends strongly 
Table 6. Bulk aging timescale for two fresh particle size distributions under different aging regimes. Condensation, coagulation, and overall aging timescales are given for $s=0.3 \%$. We assumed lognormal size distributions of fresh BC with a geometric standard deviation of 1.7 .

\begin{tabular}{|c|c|c|c|c|c|}
\hline \multirow[b]{2}{*}{$\begin{array}{l}D_{\mathrm{gm}} \\
(\mathrm{nm})\end{array}$} & \multicolumn{2}{|c|}{ Input variables } & \multicolumn{3}{|c|}{$\begin{array}{l}\text { Expected aging timescale } \\
\qquad s=0.3 \%\end{array}$} \\
\hline & $\begin{array}{l}\dot{f}_{\text {cond }} \\
\left(\mathrm{nm} \mathrm{h}^{-1}\right)\end{array}$ & $\begin{array}{l}N_{\mathrm{CCN}, \text { large }} \\
\left(\mathrm{cm}^{-3}\right)\end{array}$ & $\hat{\tau}_{\text {cond }}(\mathrm{h})$ & $\begin{array}{r}s=0.3 \% \\
\hat{\tau}_{\text {coag }}(\mathrm{h})\end{array}$ & $\hat{\tau}_{\text {age }}(\mathrm{h})$ \\
\hline 30 & 0.01 & 500 & 460 & 17 & 16 \\
\hline 60 & 0.01 & 500 & 44 & 40 & 20 \\
\hline 30 & 1 & 500 & 18 & 17 & 9 \\
\hline 60 & 1 & 500 & 2.8 & 40 & 2.6 \\
\hline 30 & 0.01 & 10000 & 460 & 5 & 5 \\
\hline 60 & 0.01 & 10000 & 44 & 6 & 5.4 \\
\hline 30 & 1 & 10000 & 18 & 2.6 & 2.2 \\
\hline 60 & 1 & 10000 & 2.8 & 6 & 2 \\
\hline
\end{tabular}
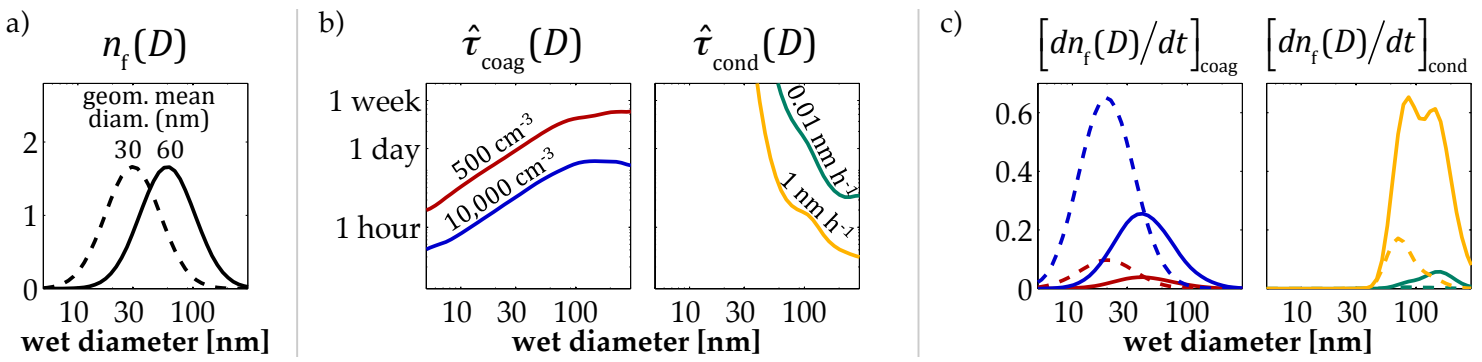

Figure 10. Rate at which particles of specific size transition from fresh to aged (c) depends on size distribution of fresh BC (a) and sizeresolved aging timescale (b). Results are shown at $s=0.3 \%$, where the size-resolved aging timescale under different conditions are determined from the regression function in Fig. 9. The line colors in panel (c) correspond to the aging conditions shown in panel (b), and the line style in panel (c) correspond to the size distributions shown in panel (a).

on the hygroscopicity of condensing aerosol $\kappa_{\text {cond }}$ and on the size distribution of fresh particles $n_{\text {fresh }}(D)$.

\subsection{Aging timescales as a function of governing parameters}

The regression surfaces $\hat{\tau}_{\text {coag }}\left(N_{\mathrm{CCN}, \text { large }}, D\right)$ and $\hat{\tau}_{\text {cond }}\left(\dot{f}_{\text {cond }}, \kappa_{\text {cond }}, D\right)$ are shown in Fig. $9 \mathrm{a}$ and $\mathrm{b}$, respectively. Figure $9 \mathrm{a}$ shows that timescales for aging by coagulation range from hours to weeks. The coagulation aging timescale decreases with the number concentration of "large", $\mathrm{CCN}$-active particles $\left(N_{\mathrm{CCN}, \text { large }}\right)$ and, for a given $N_{\mathrm{CCN} \text {,large, }}$ small BC-containing particles are more likely to age by coagulation than large BC-containing particles. On the other hand, condensation aging timescales are shortest for the largest fresh particles and, for these particles, the condensation aging timescale tends to decrease as $\dot{f}_{\text {cond }}$ or $\kappa_{\text {cond }}$ increase. The two panels in Fig. $9 \mathrm{~b}$ show $\hat{\tau}_{\text {cond }}$ as a function of $\dot{f}_{\text {cond }}$ and $D$ for secondary aerosol with differing hygroscopicity, $\kappa_{\text {cond }}=0: 1$ on the left, representing secondary organic aerosol, and $\kappa_{\text {cond }}=0: 65$ on the right, representing secondary inorganic aerosol.

\subsection{Sensitivity of aging timescale to aging conditions}

In this section we apply the regression surfaces shown in Fig. 9 to selected example cases to demonstrate how aging conditions and the fresh particle size distribution affect particle aging rates. Figure 10 shows how aging rates by condensation and coagulation can be reconstructed as a function of the size distribution of fresh particles (Fig. 10a) and the size-resolve aging timescale (Fig. 10b). We compare lognormal size distributions with geometric mean diameters $\left(D_{\mathrm{gm}}\right)$ of $30 \mathrm{~nm}$ (dashed line in Fig. 10a) and $60 \mathrm{~nm}$ (solid line of Fig. 10a). Timescales were computed for limiting environmental conditions, indicated by line colors in Fig. 10b): slow coagulation aging $\left(N_{\mathrm{CCN} \text {, large }}=500 \mathrm{~cm}^{-3}\right.$, red line $)$ or fast coagulation aging $\left(N_{\mathrm{CCN}, \text { large }}=10,000 \mathrm{~cm}^{-3}\right.$, blue line $)$ and slow condensation aging $\left(\dot{f}_{\text {cond }}=0.01 \mathrm{~nm} \mathrm{~h}^{-1}\right.$, green line) or fast condensation aging $\left(\dot{f}_{\text {cond }}=1 \mathrm{~nm} \mathrm{~h}^{-1}\right.$, yellow line). Size-resolved aging timescales are taken from the regression surfaces in Fig. 9 for these values of $\dot{f}_{\text {cond }}$ and $N_{\mathrm{CCN} \text {,large }}$, assuming $\kappa_{\text {cond }}=0.65$ in both cases. Then, the rate at which particles of a given size transition from fresh to aged (Fig. 10c) is computed as the product of $n_{\mathrm{f}}(D)$ and $1 / \tau_{\text {age }}(D)$. Figure $10 \mathrm{c}$ shows aging rates for particle distributions with $D_{\mathrm{gm}}=30 \mathrm{~nm}$ (dashed lines) and $D_{\mathrm{gm}}=60 \mathrm{~nm}$ (solid lines) under these limiting environmental conditions 
that promote rapid (blue lines) or slow (red lines) aging by coagulation and rapid (yellow lines) or slow (green lines) aging by condensation.

For these two size distributions (Fig. 10a) and different combinations of aging conditions (Fig. 10b), bulk aging timescales at $s=0.3 \%$ were computed according to Eq. (13), and the results are given in Table 6. The combinations of environmental conditions are as follows: (1) rapid condensation aging (yellow lines in Fig. 10b) and slow coagulation aging (red lines), (2) slow condensation aging (green lines) and rapid coagulation aging (blue lines), (3) slow aging by both condensation and coagulation, and (4) rapid aging by both condensation and coagulation.

The sensitivity of the bulk aging timescales to $\dot{f}_{\text {cond }}$ and $N_{\mathrm{CCN} \text {,large }}$ depends strongly on the environmental supersaturation $s$, as shown in Fig. 11. At each supersaturation, sensitivities are quantified as a logarithmic derivative, that is, the relative change in $\tau_{\text {age }}$ to a relative change in $\dot{f}_{\text {cond }}$ or $N_{\mathrm{CCN} \text {,large }}$. Negative values of this metric indicate that increasing $N_{\mathrm{CCN} \text {,large }}$ or $\dot{f}_{\text {cond }}$ corresponds to a decrease in $\tau_{\text {aging }}$.

While $\tau_{\text {aging }}$ is most sensitive to $N_{\mathrm{CCN}}$, large at low supersaturation levels, $\tau_{\text {aging }}$ shows the greatest sensitivity to $\dot{f}_{\text {cond }}$ at high supersaturation levels. At low supersaturation levels, $\tau_{\text {aging }}$ is insensitive to $\dot{f}_{\text {cond }}$ if the distribution contains a higher fraction of small particles $\left(D_{\mathrm{gm}}=30 \mathrm{~nm}\right)$, regardless of conditions for aging by coagulation. If particles are large $\left(D_{\mathrm{gm}}=60 \mathrm{~nm}\right), \tau_{\text {aging }}$ at this low $s$ is $\tau_{\text {aging }}$ sensitive to $\dot{f}_{\text {cond }}$ only under conditions of slow aging by coagulation. At $s=1 \%, \tau_{\text {aging }}$ is sensitive to $\dot{f}_{\text {cond }}$ in all cases, regardless of the fresh particle size distribution or conditions for aging by coagulation. Coagulation aging is relatively more important at low supersaturation compared to high supersaturation thresholds. Consistent with this fact, Fig. 11a shows that the sensitivity of the aging timescale to $N_{\mathrm{CCN} \text {,large gener- }}$ ally decreases as $s$ increases. The magnitude of the condensational flux $\dot{f}_{\text {cond }}$ impacts the sensitivity towards $N_{\mathrm{CCN} \text {,large }}$. Environments with lower $\dot{f}_{\text {cond }}$ result in a larger sensitivity to $N_{\mathrm{CCN} \text {,large }}$.

\section{Discussion}

Global models that employ first-order aging models assume a fixed timescale of 1-3 days, but observations show that aging timescales can be as short as a few hours in polluted areas (Zhang et al., 2008). Other modeling studies have suggested parameterizations that account for this variation in aging conditions. Riemer et al. (2004) evaluated aging timescales in a mesoscale model and parameterized timescales for aging by coagulation as a function of the overall number concentration. Pierce et al. (2009) developed an analytical expression that accounts for decreases in the number concentration of primary aerosol through coagulation events; for emitted particles of a specific size, the reduction in particle
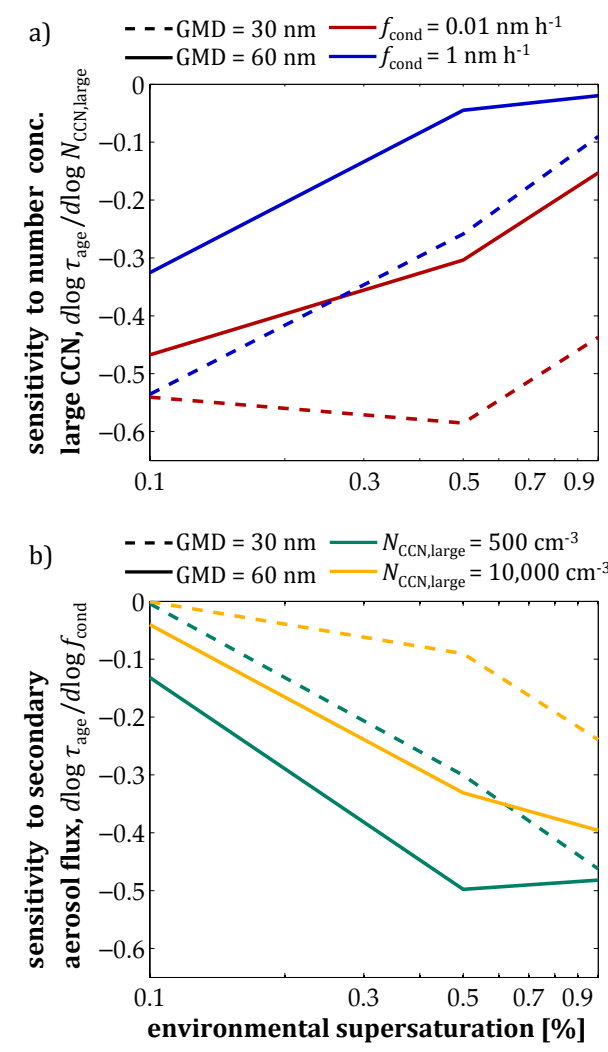

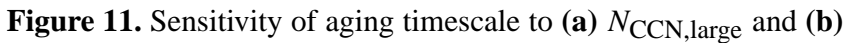
$\dot{f}_{\text {cond }}$ as a function of supersaturation level, expressed as the logarithmic derivative of the timescale with respect to each variable.

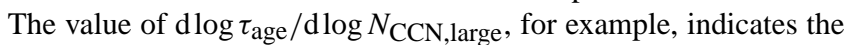
relative change in $\tau_{\text {age }}$ to a relative change in $N_{\mathrm{CCN} \text {,large }}$. Shown for the size distributions and aging conditions in Fig. 10.

number through coagulation loss rate was computed by integrating the coagulation kernel over the entire background size distribution. However, the regression analysis applied in the current study reveals that $90 \%$ of the variance in the coagulation aging timescale can be explained using a relatively simple representation of the background size distribution. We showed that the variation in the size-resolved aging timescales can be attributed to the number concentration of particles that are both large $(D>100 \mathrm{~nm})$ and CCN-active. Other characteristics of the background size distributions are not needed.

Oshima and Koike (2013) developed a parameterization of the condensation aging timescale based on results from a box model and, similar to the present study, computed aging timescales based on changes in $\mathrm{CCN}$ activity. However, unlike the present study, Oshima and Koike (2013) did not consider differences in the hygroscopic properties of the condensing material and their aging timescale varied with the mass condensation rate per total BC mass concentration. In contrast, the regression analysis in the present study reveals that the volume condensation rate per overall 
aerosol surface area is the variable that best explains variance in BC's condensation aging timescale, which is consistent with laboratory studies (Zhang et al., 2008; Khalizov et al., 2009). The present work also differs from Oshima and Koike (2013) in the representation of the aerosol size distribution. Whereas Oshima and Koike (2013) parameterized bulk aging timescales for lognormal size distributions, we presented a size-resolved aging timescale that can be applied to any arbitrary size distribution.

As in all relationships for BC's aging timescale, the value of the aging timescale depends strongly on the criterion used to distinguish fresh and aged particles. Particle activation at a specific environmental supersaturation is the aging criterion applied in this study, representing changes in particle characteristics that most affect their susceptibility to wet deposition. Table 6 shows that the value of the aging timescale depends strongly on the criterion supersaturation at which CCN activation was evaluated, consistent with Riemer et al. (2010) and Oshima and Koike (2013). Furthermore, the relative importance of condensation versus coagulation as aging processes also depends on the supersaturation threshold.

\section{Conclusions}

This study identifies the minimal set of independent variables needed to explain variance in black carbon's aging timescale. We simulated the evolution of gases and aerosols in a series of urban scenarios with the particle-resolved model PartMCMOSAIC and extracted time-dependent aging timescales based on the rate at which individual particles transition from $\mathrm{CCN}$-inactive to $\mathrm{CCN}$-active at a specified environmental supersaturation. The value of the aging timescale spanned orders of magnitude, depending on local environmental conditions and the supersaturation threshold at which $\mathrm{CCN}$ activity was evaluated. Aging timescales were shorter than an hour under conditions of rapid secondary aerosol formation, but on the order of days in the absence of secondary aerosol precursors. Condensation aging timescales exhibited more variation than coagulation aging timescales, and the relative importance of each aging mechanism depended on the size range of particles to be aged. We performed a nonparametric regression analysis on model data from 288 scenarios in order to identify the independent variables with which aging timescales are best correlated and quantified the portion of variance explained by regressions in terms of these variables. This paper is the groundwork for the development of aging parameterizations suitable for use in global models.

To our knowledge, this is the first study to apply a regression analysis to identify the minimal set of parameters needed to explain variance in black carbon aging rates. After evaluating a number of independent variables, we found that the flux of secondary aerosol, the hygroscopicity of secondary aerosol, and the size distribution of $\mathrm{CCN}$-inactive (fresh) BC-containing particles were the minimal set of pa- rameters needed to explain $80 \%$ of variance in the condensation aging timescale. On the other hand, $90 \%$ of variance in the coagulation aging timescale was explained by only two variables: the size distribution of fresh $\mathrm{BC}$-containing particles and the number concentration of particles that are both large $(D>100 \mathrm{~nm})$ and $\mathrm{CCN}$-active. This work distills the complex interactions captured by the particle-resolved model to a few input variables, all of which are tracked by existing global climate models, and is a first step toward developing physically based parameterizations of aerosol aging.

Acknowledgements. This project is funded by NASA. N. Riemer also acknowledges US EPA grant 835042. Its contents are solely the responsibility of the grantee and do not necessarily represent the official views of the US EPA. Furthermore, US EPA does not endorse the purchase of any commercial products or services mentioned in the publication. The authors are grateful to Matthew West and Peter Maginnis for their suggestions in the early stages of this work. We also thank the two anonymous reviewers for their helpful comments.

Edited by: H. Su

\section{References}

Ackerman, A., Toon, O., Stevens, D., Heymsfield, A., Ramanathan, V., and Welton, E.: Reduction of tropical cloudiness by soot, Science, 288, 1042-1047, 2000.

Aiken, A. C., Salcedo, D., Cubison, M. J., Huffman, J. A., DeCarlo, P. F., Ulbrich, I. M., Docherty, K. S., Sueper, D., Kimmel, J. R., Worsnop, D. R., Trimborn, A., Northway, M., Stone, E. A., Schauer, J. J., Volkamer, R. M., Fortner, E., de Foy, B., Wang, J., Laskin, A., Shutthanandan, V., Zheng, J., Zhang, R., Gaffney, J., Marley, N. A., Paredes-Miranda, G., Arnott, W. P., Molina, L. T., Sosa, G., and Jimenez, J. L.: Mexico City aerosol analysis during MILAGRO using high resolution aerosol mass spectrometry at the urban supersite (T0) - Part 1: Fine particle composition and organic source apportionment, Atmos. Chem. Phys., 9, 6633-6653, doi:10.5194/acp-9-6633-2009, 2009.

Albrecht, B.: Aerosols, cloud microphysics, and fractional cloudiness, Science, 245, 1227-1230, 1989.

Allan, J. D., Alfarra, M. R., Bower, K. N., Williams, P. I., Gallagher, M. W., Jimenez, J. L., McDonald, A. G., Nemitz, E., Canagaratna, M. R., Jayne, J. T., Coe, H., and Worsnop, D. R.: Quantitative sampling using an Aerodyne aerosol mass spectrometer 2. Measurements of fine particulate chemical composition in two U.K. cities, J. Geophys. Res., 108, 4090, doi:10.1029/2002JD002359, 2003a.

Allan, J. D., Jimenez, J. L., Williams, P. I., Alfarra, M. R., Bower, K. N., Jayne, J. T., Coe, H., and Worsnop, D. R.: Quantitative sampling using an Aerodyne aerosol mass spectrometer 1. Techniques of data interpretation and error analysis, J. Geophys. Res.Atmos., 4090, 108, doi:10.1029/2002JD002358, $2003 \mathrm{~b}$.

Aquila, V., Hendricks, J., Lauer, A., Riemer, N., Vogel, H., Baumgardner, D., Minikin, A., Petzold, A., Schwarz, J. P., Spackman, J. R., Weinzierl, B., Righi, M., and Dall'Amico, M.: MADE-in: 
a new aerosol microphysics submodel for global simulation of insoluble particles and their mixing state, Geosci. Model Dev., 4, 325-355, doi:10.5194/gmd-4-325-2011, 2011.

Bauer, S. E., Wright, D. L., Koch, D., Lewis, E. R., McGraw, R., Chang, L.-S., Schwartz, S. E., and Ruedy, R.: MATRIX (Multiconfiguration Aerosol TRacker of mIXing state): an aerosol microphysical module for global atmospheric models, Atmos. Chem. Phys., 8, 6003-6035, doi:10.5194/acp-8-60032008, 2008.

Bae, M.-S., Demerjian, K. L., and Schwab, J. J.: Seasonal estimation of organic mass to organic carbon in PM 2.5 at rural and urban locations in New York state, Atmos. Environ., 40, 74677479, 2006.

Binkowski, F. and Roselle, S.: Models-3 Community Multiscale Air Quality (CMAQ) model aerosol component: 1. Model description, J. Geophys. Res., 108, 4183, doi:10.1029/2001JD001409, 2003.

Cantrell, W., Shaw, G., Cass, G., Chowdhury, Z., Hughes, L., Prather, K., Guazzotti, S., and Coffee, K.: Closure between aerosol particles and cloud condensation nuclei at Kaashidhoo Climate Observatory, J. Geophys. Res., 106, 28711-28718, doi:10.1029/2000JD900781, 2001.

Cheng, Y. F., Su, H., Rose, D., Gunthe, S. S., Berghof, M., Wehner, B., Achtert, P., Nowak, A., Takegawa, N., Kondo, Y., Shiraiwa, M., Gong, Y. G., Shao, M., Hu, M., Zhu, T., Zhang, Y. H., Carmichael, G. R., Wiedensohler, A., Andreae, M. O., and Pöschl, U.: Size-resolved measurement of the mixing state of soot in the megacity Beijing, China: diurnal cycle, aging and parameterization, Atmos. Chem. Phys., 12, 4477-4491, doi:10.5194/acp-12-4477-2012, 2012.

Chin, M., Diehl, T., Tan, Q., Prospero, J. M., Kahn, R. A., Remer, L. A., Yu, H., Sayer, A. M., Bian, H., Geogdzhayev, I. V., Holben, B. N., Howell, S. G., Huebert, B. J., Hsu, N. C., Kim, D., Kucsera, T. L., Levy, R. C., Mishchenko, M. I., Pan, X., Quinn, P. K., Schuster, G. L., Streets, D. G., Strode, S. A., Torres, O., and Zhao, X.-P.: Multi-decadal aerosol variations from 1980 to 2009: a perspective from observations and a global model, Atmos. Chem. Phys., 14, 3657-3690, doi:10.5194/acp-14-3657-2014, 2014.

Clegg, S., Brimblecombe, P., and Wexler, A.: Thermodynamic model of the system $\mathrm{H}^{+}-\mathrm{NH}_{4}^{+}-\mathrm{SO}_{4}^{2-}-\mathrm{NO}_{3}^{-}-\mathrm{H}_{2} \mathrm{O}$ at tropospheric temperatures, J. Phys. Chem. A, 102, 2137-2154, 1998.

Cooke, W. and Wilson, J.: A global black carbon aerosol model, J. Geophys. Res., 101, 19395-19409, doi:10.1029/96JD00671, 1996.

Cozic, J., Verheggen, B., Mertes, S., Connolly, P., Bower, K., Petzold, A., Baltensperger, U., and Weingartner, E.: Scavenging of black carbon in mixed phase clouds at the high alpine site Jungfraujoch, Atmos. Chem. Phys., 7, 1797-1807, doi:10.5194/acp-7-1797-2007, 2007.

Croft, B., Lohmann, U., and von Salzen, K.: Black carbon ageing in the Canadian Centre for Climate modelling and analysis atmospheric general circulation model, Atmos. Chem. Phys., 5, 19311949, doi:10.5194/acp-5-1931-2005, 2005.

Cubison, M. J., Alfarra, M. R., Allan, J., Bower, K. N., Coe, H., McFiggans, G. B., Whitehead, J. D., Williams, P. I., Zhang, Q., Jimenez, J. L., Hopkins, J., and Lee, J.: The characterisation of pollution aerosol in a changing photochemical environment, Atmos. Chem. Phys., 6, 5573-5588, doi:10.5194/acp-6-5573-2006, 2006.
DeCarlo, P. F., Dunlea, E. J., Kimmel, J. R., Aiken, A. C., Sueper, D., Crounse, J., Wennberg, P. O., Emmons, L., Shinozuka, Y., Clarke, A., Zhou, J., Tomlinson, J., Collins, D. R., Knapp, D., Weinheimer, A. J., Montzka, D. D., Campos, T., and Jimenez, J. L.: Fast airborne aerosol size and chemistry measurements above Mexico City and Central Mexico during the MILAGRO campaign, Atmos. Chem. Phys., 8, 4027-4048, doi:10.5194/acp-84027-2008, 2008.

Docherty, K. S., Stone, E. A., Ulbrich, I. M., DeCarlo, P. F., Snyder, D. C., Schauer, J. J., Peltier, R. E., Weber, R. J., Murphy, S. M., Seinfeld, J. H., Grover, B. D., Eatough, D. J., and Jimenez, J. L.: Apportionment of primary and secondary organic aerosols in Southern California during the 2005 Study of Organic Aerosols in Riverside (SOAR-1), Environ. Sci. Tech., 42, 76557662, 2008.

Drewnick, F., Jayne, J. T., Canagaratna, M., Worsnop, D. R., and Demerjian, K. L.: Measurement of ambient aerosol composition during the PMTACS-NY 2001 using an aerosol mass spectrometer. part II: Chemically speciated mass distributions special issue of aerosol science and technology on findings from the fine particulate matter supersites program, Aerosol Sci. Tech., 38, 104117, 2004a.

Drewnick, F., Schwab, J. J., Jayne, J. T., Canagaratna, M., Worsnop, D. R., and Demerjian, K. L.: Measurement of ambient aerosol composition during the PMTACS-NY 2001 using an aerosol mass spectrometer. part I: Mass concentrations special issue of aerosol science and technology on findings from the fine particulate matter supersites program, Aerosol Sci. Tech., 38, 92-103, 2004b.

Dusek, U., Frank, G., Hildebrandt, L., Curtius, J., Schneider, J., Walter, S., Chand, D., Drewnick, F., Hings, S., Jung, D., Borrmann, S., and Andreae, M. O.: Size matters more than chemistry for cloud-nucleating ability of aerosol particles, Science, 312, 1375-1378, 2006.

Furutani, H., Dallsto, M., Roberts, G., and Prather, K.: Assessment of the relative importance of atmospheric aging on $\mathrm{CCN}$ activity derived from field observations, Atmos. Environ., 42, 31303142, 2008.

Hansen, J. and Nazarenko, L.: Soot climate forcing via snow and ice albedos, P. Natl. Acad. Sci. USA, 101, 423-428, doi:10.1073/pnas.2237157100, 2004.

Hings, S. S., Walter, S., Schneider, J., Borrmann, S., and Drewnick, F.: Comparison of a quadrupole and a time-of-flight aerosol mass spectrometer during the Feldberg Aerosol Characterization Experiment 2004, Aerosol Sci. Tech., 41, 679-691, 2007.

Jacobson, M.: Development and application of a new air pollution modeling system - II. Aerosol module structure and design, Atmos. Environ., 31, 131-144, 1997.

Jacobson, M. Z.: Control of fossil-fuel particulate black carbon and organic matter, possibly the most effective method of slowing global warming. J. Geophys. Res.-Atmos. (1984-2012), 107, ACH 16-1-ACH 16-22, 2002.

Jacobson, M. Z.: Climate response of fossil fuel and biofuel soot, accounting for soot's feedback to snow and sea ice albedo and emissivity, J. Geophys. Res.-Atmos., 109, D21201, doi:10.1029/2004JD004945, 2004.

Jimenez, J. L., Canagaratna, M. R., Donahue, N. M., Prevot, A. S. H., Zhang, Q., Kroll, J. H., DeCarlo, P. F., Allan, J. D., Coe, H., Ng, N. L., Aiken, A. C., Docherty K. S., Ulbrich, I. M., 
Grieshop, A. P., Robinson, A. L., Duplissy, J., Smith, J. D., Wilson, K. R., Lanz, V. A., Hueglin, C., Sun, Y. L., Tian, J., Laaksonen, A. Raatikainen, T., Rautiainen, J., Vaattovaara, P., Ehn, M., Kulmala, M., Tomlinson, J. M., Collins, D. R., Cubison, M. J., Dunlea, E. J., Huffman, J. A., Onasch, T. B., Alfarra, M. R., Williams, P. I., Bower, K., Kondo, Y., Schneider, J., Drewnick, F., Borrmann, S., Weimer, S., Demerjian, K., Salcedo, D., Cottrell, L., Griffin, R., Takami, A., Miyoshi, T., Hatakeyama, S., Shimono, A., Sun, J. Y., Zhang, Y. M., Dzepina, K,Kimmel, J. R., Sueper D., Jayne, J. T., Herndon, S. C., Trimborn, A. M., Williams, L. R., Wood, E. C., Middlebrook, A. M. Kolb, C. E., Baltensperger, U., and Worsnop, D. R.: Evolution of organic aerosols in the atmosphere, Science, 326, 1525-1529, 2009.

Jo, D., Park, R., Kim, M., and Spracklen, D.: Effects of chemical aging on global secondary organic aerosol using the volatility basis set approach, Atmos. Environ., 81, 230-244, 2013.

Johnson, K. S., Zuberi, B., Molina, L. T., Molina, M. J., Iedema, M. J., Cowin, J. P., Gaspar, D. J., Wang, C., and Laskin, A.: Processing of soot in an urban environment: case study from the Mexico City Metropolitan Area, Atmos. Chem. Phys., 5, 3033-3043, doi:10.5194/acp-5-3033-2005, 2005.

Khalizov, A. F., Zhang, R., Zhang, D., Xue, H., Pagels, J., and McMurry, P. H.: Formation of highly hygroscopic soot aerosols upon internal mixing with sulfuric acid vapor, J. Geophys. Res.Atmos., 114, D05208, doi:10.1029/2008JD010595, 2009.

Koch, D.: Transport and direct radiative forcing of carbonaceous and sulfate aerosols in the GISS GCM, J. Geophys. Res.-Atmos., 106, 20311-20332, 2001.

Koch, D., Schulz, M., Kinne, S., McNaughton, C., Spackman, J. R., Balkanski, Y., Bauer, S., Berntsen, T., Bond, T. C., Boucher, O., Chin, M., Clarke, A., De Luca, N., Dentener, F., Diehl, T., Dubovik, O., Easter, R., Fahey, D. W., Feichter, J., Fillmore, D., Freitag, S., Ghan, S., Ginoux, P., Gong, S., Horowitz, L., Iversen, T., Kirkevåg, A., Klimont, Z., Kondo, Y., Krol, M., Liu, X., Miller, R., Montanaro, V., Moteki, N., Myhre, G., Penner, J. E., Perlwitz, J., Pitari, G., Reddy, S., Sahu, L., Sakamoto, H., Schuster, G., Schwarz, J. P., Seland, Ø., Stier, P., Takegawa, N., Takemura, T., Textor, C., van Aardenne, J. A., and Zhao, Y.: Evaluation of black carbon estimations in global aerosol models, Atmos. Chem. Phys., 9, 9001-9026, doi:10.5194/acp-9-9001-2009, 2009.

Köhler, H.: The nucleus in and the growth of hygroscopic droplets, T. Faraday Soc., 32, 1152-1161, 1936.

Lanz, V. A., Alfarra, M. R., Baltensperger, U., Buchmann, B., Hueglin, C., and Prévôt, A. S. H.: Source apportionment of submicron organic aerosols at an urban site by factor analytical modelling of aerosol mass spectra, Atmos. Chem. Phys., 7, 15031522, doi:10.5194/acp-7-1503-2007, 2007.

Liu, J., Fan, S., Horowitz, L. W., and Levy, H.: Evaluation of factors controlling long-range transport of black carbon to the arctic, J. Geophys. Res.-Atmos., 116, D04307, doi:10.1029/2010JD015145, 2011.

Lohmann, U. and Feichter, J.: Global indirect aerosol effects: a review, Atmos. Chem. Phys., 5, 715-737, doi:10.5194/acp-5-7152005, 2005.

Maricq, M. M.: Chemical characterization of particulate emissions from diesel engines: a review, J. Aerosol Sci., 38, 1079-1118, 2007.
Matsui, H., Koike, M., Kondo, Y., Moteki, N., Fast, J. D., and Zaveri, R. A.: Development and validation of a black carbon mixing state resolved three-dimensional model: Aging processes and radiative impact, J. Geophys. Res.-Atmos., 118, 2304-2326, 2013.

McCormick, R. A. and Ludwig, J. H.: Climate modification by atmospheric aerosols, Science, 156, 1358-1359, 1967.

McGraw, R.: Description of aerosol dynamics by the quadrature method of moments, Aerosol Sci. Tech., 27, 255-265, 1997.

Nadaraya, E. A.: On estimating regression, Theor. Probab. Appl., 9, 141-142, 1964.

Oshima, N. and Koike, M.: Development of a parameterization of black carbon aging for use in general circulation models, Geosci. Model Dev., 6, 263-282, doi:10.5194/gmd-6-263-2013, 2013.

Oshima, N., Koike, M., Zhang, Y., and Kondo, Y.: Aging of black carbon in outflow from anthropogenic sources using a mixing state resolved model: 2. Aerosol optical properties and cloud condensation nuclei activities. J. Geophys. Res.-Atmos., 114, D06210, doi:10.1029/2008JD010680, 2009.

Petters, M., Prenni, A., Kreidenweis, S., DeMott, P., Matsunaga, A., Lim, Y., and Ziemann, P.: Chemical aging and the hydrophobicto-hydrophilic conversion of carbonaceous aerosol, Geophys. Res. Lett., 33, L24806, doi:10.1029/2006GL027249, 2006.

Petters, M. D. and Kreidenweis, S. M.: A single parameter representation of hygroscopic growth and cloud condensation nucleus activity, Atmos. Chem. Phys., 7, 1961-1971, doi:10.5194/acp-71961-2007, 2007.

Pierce, J., Theodoritsi, G., Adams, P., and Pandis, S.: Parameterization of the effect of sub-grid scale aerosol dynamics on aerosol number emission rates, J. Aerosol Sci., 40, 385-393, 2009.

Prenni, A., Petters, M., Kreidenweis, S., DeMott, P., and Ziemann, P.: Cloud droplet activation of secondary organic aerosol, J. Geophys. Res., 112, 10223, doi:10.1029/2006JD007963, 2007.

Riemer, N., Vogel, H., and Vogel, B.: Soot aging time scales in polluted regions during day and night, Atmos. Chem. Phys., 4, 1885-1893, doi:10.5194/acp-4-1885-2004, 2004.

Riemer, N., West, M., Zaveri, R., and Easter, R.: Simulating the evolution of soot mixing state with a particleresolved aerosol model, J. Geophys. Res., 114, D09202, doi:10.1029/2008JD011073, 2009.

Riemer, N., West, M., Zaveri, R., and Easter, R.: Estimating black carbon aging time-scales with a particle-resolved aerosol model, J. Aerosol Sci., 41, 143-158, 2010.

Rose, D., Gunthe, S. S., Su, H., Garland, R. M., Yang, H., Berghof, M., Cheng, Y. F., Wehner, B., Achtert, P., Nowak, A., Wiedensohler, A., Takegawa, N., Kondo, Y., Hu, M., Zhang, Y., Andreae, M. O., and Pöschl, U.: Cloud condensation nuclei in polluted air and biomass burning smoke near the mega-city Guangzhou, China - Part 2: Size-resolved aerosol chemical composition, diurnal cycles, and externally mixed weakly CCN-active soot particles, Atmos. Chem. Phys., 11, 2817-2836, doi:10.5194/acp-112817-2011, 2011.

Rosen, H., Hansen, A., Gundel, L., and Novakov, T.: Identification of the optically absorbing component in urban aerosols, Appl. Optics, 17, 3859-3861, 1978.

Schell, B., Ackermann, I. J., Hass, H., Binkowski, F. S., and Ebel, A.: Modeling the formation of secondary organic aerosol within a comprehensive air quality model system, J. Geophys. Res. D. Atmos., 106, 8275-8293, 2001. 
Schmidt, G. A., Kelley, M., Nazarenko, L., Ruedy, R., Russell, G. L., Aleinov, I., Bauer, M. Bauer, S. E., Bhat, M. K., Bleck, R., Canuto, V., Chen, Y. H., Cheng, Y., Clune, T. L., Del Genio, A., de Fainchtein, R., Faluvegi, G., Hansen, J. E., Healy, R. J., Kiang, N. Y., Koch, D. Lacis, A. A., LeGrande, A. N., Lerner, J., Lo, K. K. Matthews, E. E., Menon, S., Miller, R. L., Oinas, V., Oloso, A. O., Perlwitz, J. P., Puma, M. J., Putman, W. M., Rind, D., Romanou, A., Sato, M., Shindell, D. T., Sun, S., Syed, R. A., Tausnev, N., Tsigaridis, K., Unger, N., Voulgarakis, A., Yao, M.-S., and Zhang, J.: Configuration and assessment of the GISS ModelE2 contributions to the CMIP5 archive, J. Adv. Model. Earth Syst., 6, 141-184, doi:10.1002/2013MS000265, 2014.

Schulz, M., Textor, C., Kinne, S., Balkanski, Y., Bauer, S., Berntsen, T., Berglen, T., Boucher, O., Dentener, F., Guibert, S., Isaksen, I. S. A., Iversen, T., Koch, D., Kirkevåg, A., Liu, X., Montanaro, V., Myhre, G., Penner, J. E., Pitari, G., Reddy, S., Seland, $\varnothing$., Stier, P., and Takemura, T.: Radiative forcing by aerosols as derived from the AeroCom present-day and pre-industrial simulations, Atmos. Chem. Phys., 6, 5225-5246, doi:10.5194/acp-65225-2006, 2006.

Silverman, B.: Density Estimation for Statistics and Data Analysis, vol. 26, Chapman \& Hall/CRC, New York, 86-87, 1986.

Sun, J., Zhang, Q., Canagaratna, M. R., Zhang, Y., Ng, N. L., Sun, Y., Jayne, J. T., Zhang, X., Zhang, X., and Worsnop, D. R.: Highly time-and size-resolved characterization of submicron aerosol particles in Beijing using an Aerodyne aerosol mass spectrometer, Atmos, Environ,, 44, 131-140, 2010

Svenningsson, B., Rissler, J., Swietlicki, E., Mircea, M., Bilde, M., Facchini, M. C., Decesari, S., Fuzzi, S., Zhou, J., Mønster, J., and Rosenørn, T.: Hygroscopic growth and critical supersaturations for mixed aerosol particles of inorganic and organic compounds of atmospheric relevance, Atmos. Chem. Phys., 6, 1937-1952, doi:10.5194/acp-6-1937-2006, 2006.

Takegawa, N., Miyakawa, T., Kondo, Y., Jimenez, J., Zhang, Q., Worsnop, D., and Fukuda, M.: Seasonal and diurnal variations of submicron organic aerosol in Tokyo observed using the aerodyne aerosol mass spectrometer, J. Geophys. Res.-Atmos., 111, D11206, doi:10.1029/2005JD006515, 2006.

Takegawa, N., Miyazaki, Y., Kondo, Y., Komazaki, Y., Miyakawa, T., Jimenez, J., Jayne, J., Worsnop, D., Allan, J., and Weber, R.: Characterization of an Aerodyne aerosol mass spectrometer (AMS): Intercomparison with other aerosol instruments, Aerosol Sci. Tech., 39, 760-770, 2005.

Topping, D., Coe, H., McFiggans, G., Burgess, R., Allan, J., Alfarra, M., Bower, K., Choularton, T., Decesari, S., and Facchini, M. C.: Aerosol chemical characteristics from sampling conducted on the island of Jeju, Korea during ACE ASIA, Atmos. Environ., 38, 2111-2123, 2004.

Twomey, S.: The influence of pollution on the shortwave albedo of clouds, J. Atmos. Sci., 34, 1149-1152, 1977.

Twomey, S., Piepgrass, M., and Wolfe, T.: An assessment of the impact of pollution on global cloud albedo, Tellus B, 36, 356366, 1984

Watson, G. S.: Smooth regression analysis, Sankhya Ser. A, 26, 359-372, 1964

Weimer, S., Drewnick, F., Hogrefe, O., Schwab, J. J., Rhoads, K., Orsini, D., Canagaratna, M., Worsnop, D. R., and Demerjian, K. L.: Size-selective nonrefractory ambient aerosol mea- surements during the Particulate Matter Technology Assessment and Characterization Study-New York 2004 Winter Intensive in New York City, J. Geophys. Res.-Atmos., 111, D18305, doi:10.1029/2006JD007215, 2006.

Weingartner, E., Burtscher, H., and Baltensperger, U.: Hygroscopic properties of carbon and diesel soot particles, Atmos. Environ. 31, 2311-2327, 1997.

Wexler, A., Lurmann, F., and Seinfeld, J.: Modelling urban and regional aerosols-I. model development, Atmos. Environ., 28, 531-546, 1994.

Wilson, J., Cuvelier, C., and Raes, F.: A modeling study of global mixed aerosol fields, J. Geophys. Res.-Atmos., 106, 3408134108, 2001.

Zaveri, R. and Peters, L.: A new lumped structure photochemical mechanism for large-scale applications, J. Geophys. Res., 104, 30387-30415, doi:10.1029/1999JD900876, 1999.

Zaveri, R., Easter, R., and Peters, L.: A computationally efficient Multicomponent Equilibrium Solver for Aerosols (MESA), J. Geophys. Res., 110, D24203, doi:10.1029/2004JD005618, 2005a.

Zaveri, R., Easter, R., and Wexler, A.: A new method for multicomponent activity coefficients of electrolytes in aqueous atmospheric aerosols, J. Geophys. Res., 110, D02201, doi:10.1029/2004JD005618, 2005 b.

Zaveri, R., Easter, R., Fast, J., and Peters, L.: Model for Simulating Aerosol Interactions and Chemistry (MOSAIC), J. Geophys. Res., 113, D13204, doi:10.1029/2007JD008782, 2008.

Zaveri, R. A., Barnard, J. C., Easter, R. C., Riemer, N., and West, M.: Particle-resolved simulation of aerosol size, composition, mixing state, and the associated optical and cloud condensation nuclei activation properties in an evolving urban plume, J. Geophys. Res.-Atmos., D17210, 115, doi:10.1029/2009JD013616, 2010.

Zhang, Q., Stanier, C. O., Canagaratna, M. R., Jayne, J. T.,Worsnop, D. R., Pandis, S. N., and Jimenez, J. L.: Insights into the chemistry of new particle formation and growth events in Pittsburgh based on aerosol mass spectrometry, Environ. Sci. Tech., 38, 4797-4809, 2004.

Zhang, Q., Alfarra, M. R., Worsnop, D. R., Allan, J. D., Coe, H., Canagaratna, M. R., and Jimenez, J. L.: Deconvolution and quantification of hydrocarbon-like and oxygenated organic aerosols based on aerosol ss spectrometry, Environ. Sci. Tech., 39, 49384952, 2005a.

Zhang, Q., Canagaratna, M. R., Jayne, J. T., Worsnop, D. R., and Jimenez, J. L.: Time-and size-resolved chemical composition of submicron particles in Pittsburgh: Implications for aerosol sources and processes, J. Geophys. Res.-Atmos., 110, D07S09, doi:10.1029/2004JD004649, 2005b.

Zhang, Q., Worsnop, D. R., Canagaratna, M. R., and Jimenez, J. L.: Hydrocarbon-like and oxygenated organic aerosols in Pittsburgh: insights into sources and processes of organic aerosols, Atmos. Chem. Phys., 5, 3289-3311, doi:10.5194/acp-5-32892005, 2005c

Zhang, Q., Jimenez, J. L., Worsnop, D. R., and Canagaratna, M.: A case study of urban particle acidity and its influence on secondary organic aerosol, Environ. Sci. Tech., 41, 3213-3219, 2007. 
Zhang, R., Khalizov, A. F., Pagels, J., Zhang, D., Xue, H., and McMurry, P. H.: Variability in morphology, hygroscopicity, and optical properties of soot aerosols during atmospheric processing, P. Natl. Acad. Sci. USA, 105, 10291-10296, 2008.
Zuberi, B., Johnson, K., Aleks, G., Molina, L., Molina, M., and Laskin, A.: Hydrophilic properties of aged soot, Geophys. Res. Lett., 32, L01807, doi:10.1029/2004GL021496, 2005. 